NBER WORKING PAPER SERIES

\title{
ON THE TIMING OF INNOVATION IN STOCHASTIC SCHUMPETERIAN GROWTH MODELS
}

\author{
Gadi Barlevy \\ Working Paper 10741 \\ http://www.nber.org/papers/w10741 \\ NATIONAL BUREAU OF ECONOMIC RESEARCH \\ 1050 Massachusetts Avenue \\ Cambridge, MA 02138 \\ September 2004
}

I am grateful to Jeff Campbell, Marty Eichenbaum, Huw Lloyd-Ellis, Kiminori Matsuyama, Alex Monge, Joanne Roberts, Fabrizio Zilibotti, and two anonymous referees for their comments, as well as seminar participants at Northwestern, the Stockholm School of Economics, Queens' University, the Chicago Fed, the NBER, the Canadian Macro Study Group, and the Society of Economic Dynamics. The views expressed here do not necessarily reflect the position of the Federal Reserve Bank of Chicago or the Federal Reserve System. The views expressed herein are those of the author(s) and not necessarily those of the National Bureau of Economic Research.

(C2004 by Gadi Barlevy. All rights reserved. Short sections of text, not to exceed two paragraphs, may be quoted without explicit permission provided that full credit, including (C) notice, is given to the source. 
On the Timing of Innovation in Stochastic Schumpeterian Growth Models

Gadi Barlevy

NBER Working Paper No. 10741

September 2004

JEL No. E32, O3, D62

\begin{abstract}
$\underline{\text { ABSTRACT }}$
Recent work has revived the Schumpeterian hypothesis that recessions facilitate innovation and growth. But a major source of productivity growth, research and development, is actually procyclical. This paper argues that while it is optimal to concentrate growth-enhancing activities in downturns, dynamic spillovers inherent to the $R \& D$ process lead private agents to concentrate too much of their R\&D activity in booms, precisely when its social cost is highest. Thus, while previous literature has argued recessions promote growth and intertemporal substitution is a desirable consequence of fluctuations, in the case of $\mathrm{R} \& \mathrm{D}$ recessions discourage growth and intertemporal substitution proves to be a social liability.

Gadi Barlevy Economic Research Department Federal Reserve Bank of Chicago 230 South La Salle

Chicago, IL 60604

and NBER

gbarlevy@ frbchi.org
\end{abstract}




\section{Introduction}

Over the past decade, economists have resurrected the Schumpeterian notion that recessions facilitate long-run economic growth. Modern reincarnations of this hypothesis are rooted in theories of intertemporal substitution. ${ }^{1}$ That is, they assume that productivity-enhancing activities compete with production activities for resources. Since the cost of growth-enhancing activities in terms of forgone output or sales is lower in recessions, there will be incentive to reallocate resources toward such activities in these periods. Recessions should therefore promote the use of resources in growth-enhancing activities, and it is even possible for cyclical fluctuations to increase welfare by allowing the economy to grow at a lower overall cost.

In contrast to the above theory, empirical evidence suggests that one of the major sources of long-run productivity growth - research and development (henceforth $R \& D$ ) - is in fact procyclical. For example, Griliches (1990) reports that both R\&D and its output, patents, are higher in booms. ${ }^{2}$ Fatas (2000) similarly reports that growth in real R\&D expenditures is positively correlated with contemporaneous output growth in the U.S., although this correlation has been less pronounced since the 1980s. More recently, Comin and Gertler (2004) argue that R\&D in the U.S. is especially procyclical at frequencies of between 8 and 50 years. That is, even if R\&D does not vary consistently with GDP growth at high frequencies, periods of sustained low output growth are associated with sustained low R\&D growth.

Why is R\&D inconsistent with intertemporal substitution? One possibility is that contrary to the theory, R\&D does not compete with production for resources. As Aghion and Saint Paul (1998) demonstrate, if $\mathrm{R} \& \mathrm{D}$ requires produced goods as opposed to factor inputs, the fact that more goods are produced in booms allows for more R\&D activity in upswings. ${ }^{3}$ But Aghion and Saint Paul are also quick to dismiss this scenario. Indeed, as Griliches (1984) observes, the

\footnotetext{
${ }^{1}$ Examples include Hall (1991, 2000), Mortensen and Pissarides (1994), and Gomes, Greenwood, Rebelo (2001) who study search; Cooper and Haltiwanger (1993), Aghion and Saint Paul (1998), and Canton and Uhlig (1999) who study technical change; and DeJong and Ingram (2001), Dellas and Sakellaris (2003), and Barlevy and Tsiddon (2004), who study human capital accumulation.

${ }^{2}$ The fact that patents are synchronized with the business cycle might seem surprising given the presumed lags inherent to the research process. However, Griliches argues these lags are short, noting that "the evidence is quite strong that when a firm changes its $R \& D$ expenditures, parallel changes occur also in its patent numbers. The relationship is close to contemporaneous with some lag effects which are small and not well estimated (Hall, Griliches, and Hausman, 1986). This is consistent with the observation that patents tend to be taken out relatively early in the life of a research project." (p1674).

${ }^{3}$ Following Rivera-Batiz and Romer (1991), this is known as the lab-equipment model. Comin and Gertler (2004) also assume R\&D uses final goods and note this assumption helps to generate procyclical R\&D.
} 
main input into R\&D is labor, not produced goods. Moreover, productivity in the goods sector is procyclical, even after correcting for variable utilization as in Burnside, Eichenbaum, and Rebelo (1993) and Basu (1996), while Griliches (1990) finds productivity in the R\&D sector (with patents as a proxy for output) is acyclical. This suggests the economic cost of R\&D is lower in recessions. Reconciling between the theory and the data forces us to explain why R\&D is procyclical even though its opportunity cost is countercyclical.

This paper argues that the failure to take advantage of intertemporal substitution is due to a distortion inherent to the R\&D process. Specifically, when an innovator patents a new idea, he reveals his insights to others and allows them to build on and further profit from these insights, even at his own expense if their ideas render his original innovation obsolete. As already noted by Grossman and Helpman (1991) and Aghion and Howitt (1992), the fact that innovators cannot appropriate these indirect benefits can lead to too little steady-state R\&D activity. But there is also an important temporal aspect to this externality that previous work has ignored, and which holds the key to why there might be a procyclical bias in equilibrium R\&D.

To be more precise, since rival innovators are more likely to succeed in improving on an innovation the more time they have to carry out their own $\mathrm{R} \& \mathrm{D}$, the benefits from a new discovery that pay off further in the future are more likely to accrue to someone other than the innovator who originated it. As a result, the incentives for innovators to engage in $R \& D$ will largely depend on the short-term benefits of successful innovation. If profits are procyclical, as is true in the data, innovators chasing after short-term profits will tend to concentrate relatively more of their R\&D in boom periods than is socially optimal. If profits are sufficiently procyclical, as will be the case when production entails fixed costs, equilibrium R\&D will turn procyclical, even as optimal R\&D remains countercyclical. Whereas previous work would suggest that the ability to vary innovation activity over time is a virtue of aggregate fluctuations, this paper suggests that entrepreneurs who are free to vary their innovation activity concentrate it at precisely the wrong time and impose a social liability.

The paper is organized as follows. Section 1 reviews the evidence on the procyclicality of R\&D and argues that it cannot be explained away by financial constraints. Section 2 formalizes the intuition for why equilibrium innovation suffers from a procyclical bias. Section 3 extends these results in a more realistic environment that can be analyzed quantitatively. Section 4 conjectures whether the results would survive additional modifications such as diffusion lags and strategic delay. Section 5 concludes. 


\section{Empirical Evidence}

I begin by reviewing the evidence on the cyclicality of R\&D that I ultimately intend to explain. Figure 1 plots the growth rate of real GDP against the growth rate of two measures of R\&D growth. First, as in previous work, I consider the growth rate of inflation-adjusted expenditures on $R \& D$ performed and funded by private industry, as reported by the National Science Foundation (NSF). I also use the growth rate of full-time equivalent R\&D scientists and engineers employed in companies performing $\mathrm{R} \& \mathrm{D}$. This index is cruder in that it only considers part of the inputs into $R \& D$, but it has the advantage that it doesn't depend on the price of $R \& D$ inputs. This is important, since the only price index with which to deflate nominal expenditures over the period as a whole is an aggregate index that may not accurately reflect changes in the price of R\&D inputs over the cycle.

As evident from the figure, the two series track each other relatively closely. They also track real GDP growth. Quite strikingly, the growth rate of R\&D declines in nearly all of the NBER recessions prior to 1980. However, the behavior of R\&D in NBER recessions appears to be less stable in the second half of the sample. For example, growth in R\&D was essentially flat through the 1980 recession. While growth in R\&D employment fell in the 1991 recession, growth in R\&D expenditures only started to decline after the recession ended. Conversely, although R\&D expenditures fell dramatically during the 2001 recession, employment growth in $R \& D$ already began to decline several years earlier. But even if the exact timing does not always correspond to NBER dating conventions between 1980 and 2002, R\&D growth and GDP growth remain positively correlated over this period as well.

Additional data on $\mathrm{R} \& \mathrm{D}$ expenditures comes from individual firm financial statements. The Standard \& Poor's Compustat database compiles such data for publicly traded companies. Although this sample does not capture all of the R\&D activity in the NSF data, large firms account for the vast majority of R\&D activity, and so this sample should capture the bulk of aggregate $R \& D$. Figure 2 reports the average growth rate of real $R \& D$ over the previous year among all firms reporting positive $R \& D$ spending, together with private $R \& D$ as reported by the NSF. The two series again track each other quite closely; if anything, R\&D growth among Compustat firms is even more synchronized with the cycle, since unlike the NSF data, growth in R\&D expenditures among these firms declines in both the 1958 and 1991 recessions.

A virtue of the Compustat database is that since it contains additional information on individual firms, we can use it to investigate certain hypotheses about the evolution of R\&D over the cycle. In particular, one potential explanation for the procyclical nature of $R \& D$ is that 
although firms would like to concentrate their innovation in downturns, it is harder to finance these activities in downturns. Since R\&D can only pay off after initial investments are undertaken, it may be particularly sensitive to financing constraints. To investigate this possibility, I look at the growth of $\mathrm{R} \& \mathrm{D}$ expenditures among firms that ought to be relatively unconstrained in their borrowing. If credit market frictions account for the procyclical pattern in $R \& D$, the growth in R\&D expenditures should appear less procyclical for this group.

I consider two measures of financial constraints. One measure is the cash flow available to the firm, which would mitigate the need to borrow externally in order to finance expenditures. This leads me to consider the growth rate of $\mathrm{R} \& \mathrm{D}$ expenditures for firms that report at least $\$ 50$ million of cash (in 1996 dollars) in the year in which they undertake R\&D, i.e. the top quintile of firms as ranked by their cash flow. An alternative measure is the net worth of a firm, which can be used as collateral against which the firm can borrow. This leads me to consider the growth rate of $\mathrm{R} \& \mathrm{D}$ expenditures for firms that report at least $\$ 150$ million in net worth (in 1996 dollars) in the year in which they undertake R\&D. Not surprisingly, there is a fair degree of overlap in the two samples, although they are not identical. Figure 3 illustrates the growth rate of real $R \& D$ expenditures for these two groups. The growth rate of R\&D among these relatively unconstrained firms is actually more procyclical than for the sample as a whole, and the growth rate of their R\&D systematically falls in every NBER recession.

It therefore appears that even firms that are free to concentrate their $R \& D$ in downturns choose not to do so, despite evidence in the Introduction that the opportunity cost of R\&D is countercyclical. The next section explores why firms might optimally behave this way.

\section{A Model of Schumpeterian Growth}

To analyze R\&D choices over the cycle, I consider a variation of the Grossman and Helpman (1991) quality-ladder model in which the relative productivity of the goods sector fluctuates over time. For now, I impose restrictions on preferences and technology that provide analytical tractability and help to convey the intuition for the results. I relax these in the next section.

The economy consists of a representative agent whose instantaneous utility is given by

$$
U\left(C_{t}\right)=C_{t}
$$

I relax the assumption of risk neutrality in the next section. As will be clear below, it plays an important but not essential role in the analysis. Utility is discounted at rate $\rho$ per unit time. 
The agent is endowed with a constant labor endowment $L$ pet unit time and an initial capital stock normalized to one. Capital is not accumulable and does not depreciate, i.e. it is essentially a fixed factor (e.g. land). This assumption will also be relaxed in the next section. Labor and capital can be converted into consumption goods according to a two-stage process. First, labor is converted into a series of intermediate goods indexed by $j \in[0,1]$. Second, intermediate goods are combined with capital to produce a non-storable consumption good.

For the production of consumption goods, I assume $K_{t}$ units of capital and $x_{j t}$ units of each intermediate good $j$ yield $Y_{t}$ units of the consumption good, where

$$
Y_{t}=z_{t} K_{t}^{\alpha} X_{t}^{1-\alpha}
$$

Here $z_{t}$ reflects productivity in the final goods sector and

$$
X_{t}=\exp \left[\int_{0}^{1} \ln x_{j t} d j\right]
$$

is a Cobb-Douglas composite of the intermediate goods $x_{j t}$. To capture the fact that productivity in the goods sector varies over time, I let $z_{t}$ follow a Markov switching process between two states, $Z_{1} \geq Z_{0}$, with a constant hazard rate $\mu$. I treat these fluctuations as exogenous, although one could potentially derive them endogenously. ${ }^{4}$

Turning next to the production for intermediate goods, I assume each good $j \in[0,1]$ can be produced from labor according to a linear technology

$$
x_{j t}=\lambda_{j t} L_{j t}
$$

where $L_{j t}$ denotes the amount of labor employed in the production of good $j$ at date $t$. The coefficient $\lambda_{j t}$ is given by

$$
\lambda_{j t}=\lambda^{m_{j t}}
$$

where $\lambda>1$ is a constant and $m_{j t}$ is an integer that denotes the generation of technology used for producing good $j$ at date $t$. Each good $j$ starts out at generation $m_{j 0}$, respectively, but agents can advance to higher-generation technologies by engaging in research. That is, starting with generation $m_{j}$, devoting $R_{j}$ units of labor to research on good $j$ gives rise to a hazard $\phi R_{j}$ of discovering generation $m_{j}+1$ in the next instant, which will be more productive given $\lambda>1$. Once a new generation is discovered, research can begin on the next generation. Let

$$
M_{t}=\int_{0}^{1} m_{j t} d j
$$

\footnotetext{
${ }^{4}$ For example, Benhabib and Farmer (1994) describe an economy with spillovers in which there are equilibria where the scale of production, and thus the productivity of individual producers, fluctuates over time.
} 
denote the average generation across goods. Subject to certain regularity conditions, the law of large numbers holds and implies $\dot{M}_{t}=\phi R_{t}$ where $R_{t}=\int_{0}^{1} R_{j t} d j$ denotes aggregate employment in $R \& D$. In line with the evidence on the acyclicality of productivity in R\&D sector cited in the Introduction, I assume $\phi$ is fixed over time.

It will prove convenient to express the output of final goods directly in terms of labor resources. Suppose each sector uses the same amount of labor, i.e. $L_{j t}=L-R_{t}$. One can show that this allocation is optimal and is satisfied in equilibrium. Using the fact that the supply of capital is normalized to 1, output can be expressed directly in terms of labor:

$$
Y_{t}=z_{t} X_{t}^{1-\alpha}=z_{t}\left[\lambda^{M_{t}}\left(L-R_{t}\right)\right]^{1-\alpha}
$$

The indirect productivity of labor in terms of final goods thus depends on both an exogenous term $z_{t}$ and an endogenous term $\lambda^{(1-\alpha) M_{t}}$. Assuming a two-stage production structure offers a convenient way to decompose the two terms: productivity in the final goods sector is exogenous while productivity in the intermediate goods sector is endogenous (and responds to exogenous changes in $z_{t}$ ). The growth rate of the endogenous component of labor productivity is given by

$$
\frac{d}{d t} \lambda^{(1-\alpha) M_{t}}=(1-\alpha) \dot{M}_{t} \ln \lambda=(1-\alpha) \phi R_{t} \ln \lambda
$$

Since the utility of the agent is finite only if this growth rate does not exceed the discount rate $\rho$, an optimal policy exists only if utility is bounded for any feasible innovation, i.e.

$$
\rho>(1-\alpha) \phi L \ln \lambda
$$

It is clear from (2.6) and (2.7) that the essential tradeoff facing this economy is whether to use labor resources to produce output or promote growth: faster growth requires a higher level of $R_{t}$, but this leaves fewer resources for current consumption. ${ }^{5}$

In the next two subsections, I solve for the optimal and equilibrium paths of $R_{t}$ and argue that equilibrium R\&D suffers from a procyclical bias, i.e. there is too much R\&D activity in booms than is socially optimal. Nevertheless, equilibrium R\&D is countercyclical. The reason for this is that the model counterfactually predicts equilibrium profits are just as volatile as the cost of R\&D. To understand why R\&D might be procyclical, then, it is essential to also understand why profits are so volatile over the cycle. In the last subsection, I argue that the high volatility of profits is due to the presence of fixed costs, which my analysis ignores. When I incorporate fixed costs into the analysis, equilibrium $R \& D$ will turn procyclical, even though the optimal path is countercyclical.

\footnotetext{
${ }^{5}$ One might ask whether specialized labor employed in $\mathrm{R} \& \mathrm{D}$ is really a substitute for production workers. While some R\&D expenditures involve scientists and engineers who may not be easily shifted to production, NSF data suggests that on average $40 \%$ of wage payments in R\&D is allocated to support staff.
} 


\subsection{The Social Planner's Problem}

The neo-Schumpeterian view argues that concentrating innovation in periods of low productivity in the goods sector is desirable because it helps to reduce the overall cost of achieving productivity growth. Solving the planning problem that maximizes the utility of the agent confirms this intuition. Formally, let $Z_{i}$ for $i \in\{0,1\}$ denote the initial level of productivity and recall that $M_{0}$ denotes the initial value of the average generation across all goods. The expected utility of the agent under the optimal path starting from $z_{0}=Z_{i}$ is given by

$$
V_{i}\left(M_{0}\right)=\max _{R_{t}} E\left[\int_{0}^{\infty} z_{t}\left[\lambda^{M_{t}}\left(L-R_{t}\right)\right]^{1-\alpha} e^{-\rho t} d t \mid z_{0}=Z_{i}\right]
$$

subject to the constraint

$$
\dot{M}_{t}=\phi R_{t}
$$

We can rewrite (2.9) recursively as

$$
\rho V_{i}(M)=\max _{R \in[0, L]}\left\{Z_{i}\left[\lambda^{M}(L-R)\right]^{1-\alpha}+\mu\left(V_{-i}(M)-V_{i}(M)\right)+\frac{\partial V_{i}}{\partial M} \phi R\right\}
$$

where $V_{-i}(M)$ denotes the function evaluated at the level of productivity other than $Z_{i}$. Given the stationarity of the environment, the planner will choose a constant level of employment $R$ for a given $Z_{i}$. Thus, the task of finding an optimal policy reduces to finding a pair of numbers $\left(R_{0}, R_{1}\right)$. The next proposition establishes the existence of an optimal path and argues it will undertake more innovation when productivity in the final goods sector is low. It is a special case of the more general Proposition 3 below. The proof of that proposition, along with those of all remaining propositions, is contained in an Appendix.

Proposition 1: If (2.8) is satisfied, there exists a unique solution to the social planner's problem, and innovation is (weakly) countercyclical along the optimal path, i.e. $R_{0} \geq R_{1}$.

It should be noted that while concentrating innovation when $z_{t}$ is low allows the economy to achieve growth at a lower cost, it also makes output more volatile: fewer inputs will be allocated to the production of goods precisely when productivity in that sector is already low. This is irrelevant given the agent is assumed to be risk neutral. But it will matter when the agent is risk averse, as I assume in the next section.

\subsection{Decentralized Equilibrium}

I now turn to the decentralized equilibrium of this economy. Production is assumed to be carried out by profit-maximizing firms. The technology for producing final goods is freely available, so 
profits in this sector will equal zero in equilibrium. Intermediate goods producers, by contrast, enjoy some degree of market power; the entrepreneur that discovers the $m$-th generation for producing good $j$ maintains a patent that grants him exclusive rights to use this technology. Since no firm would undertake innovation without patent protection, some monopoly power is necessary to sustain growth.

An equilibrium is a set of prices and quantities that are consistent with individual optimization and market clearing. Since the demand for intermediate goods is unit elastic under the CobbDouglas aggregator $X$, it will be optimal for an intermediate-goods producer to charge as high a price as possible. However, he cannot charge more than the marginal cost of his next most efficient competitor, or else the latter will steal away his business. In equilibrium, then, only the monopolist with the most productive technology will supply goods, at a price $p_{j t}$ equal to the marginal cost of his most efficient competitor. As Grossman and Helpman observe, incumbent producers benefit less from extending their lead than new entrants benefit from overtaking the lead, so only entrants engage in innovation in equilibrium. Hence, the next most efficient producer will use the $\left(m_{j t}-1\right)$-th generation technology. ${ }^{6}$ Normalizing the wage to 1 , the marginal cost of the next most efficient producer is $\lambda^{-\left(m_{j t}-1\right)}$, the number of labor units he requires to produce a unit of good $j$.

Let $e_{j t}=p_{j t} x_{j t}$ denote total expenditures by final goods producers on intermediate good $j$. Given the Cobb-Douglas specification for $X$, final goods producers will equalize expenditures across intermediate good $j$, i.e.

$$
e_{j t}=(1-\alpha) P_{t} Y_{t} \equiv e_{t}
$$

where $P_{t}$ denotes the price of the final good. With the wage normalized to 1 , the cost of production is just the number of employed workers $\lambda^{-m_{j t}} x_{j t}$. Since $x_{j t}=e_{t} / p_{j t}$, this cost is equal to $\lambda^{-1} e_{t}$. Hence, the profits of the incumbent firm that supplies good $j$ are given by

$$
\pi_{j t}=e_{t}-\lambda^{-1} e_{t}=\left(1-\lambda^{-1}\right)(1-\alpha) P_{t} Y_{t}
$$

Note that profits are the same for all intermediate goods, regardless of $m_{j t}$. Since total spending on consumption goods must equal the income of the representative agent in equilibrium, we can express $P_{t} Y_{t}$ as the sum of aggregate profits $\Pi_{t}$ and payments to factors,

$$
\begin{aligned}
P_{t} Y_{t} & =\Pi_{t}+r_{t} K+L \\
& =\int_{0}^{1} \pi_{j t} d j-R_{t}+r_{t} K+L
\end{aligned}
$$

\footnotetext{
${ }^{6}$ As in Grossman and Helpman (1991), this requires that R\&D expenditures are unobservable, so an incumbent has no incentive to undertake R\&D simply to discourage potential entry.
} 
where $r_{t}$ denotes the rental rate on capital at date $t$. Substituting in for $\pi_{j t}$ and using the fact that $r_{t} K=\alpha P_{t} Y_{t}$ allows us to express individual profits $\pi_{j t}$ in terms of $R_{t}$ :

$$
\pi_{j t}=(\lambda-1)\left(L-R_{t}\right)
$$

Note that nominal profits do not depend on $z_{t}$. This implies that for a fixed level of innovation $R$, the ratio of profits to the numeraire good, labor, is constant over the cycle. In practice, though, profits are far more volatile than the cost of labor (or more precisely than the cost of R\&D). This observation will figure prominently below.

Entrepreneurs who succeed in innovation earn profits (2.12) as long as their technology is the most advanced. To calculate the value of a successful innovation, let $\mathbb{I}_{j t}$ denote an indicator which equals 1 if the entrepreneur is the leading-edge producer of good $j$ and zero otherwise, and $v_{j}$ denote the value to a claim on the profits of a successful innovation at date 0 . Since the representative agent owns all claims in equilibrium, the price $v_{j}$ must leave him indifferent between buying and selling an additional claim. This indifference condition implies

$$
\begin{aligned}
v_{j} & =E\left[\int_{0}^{\infty} \mathbb{I}_{j t} \cdot \frac{U^{\prime}\left(C_{t}\right) / P_{t}}{U^{\prime}\left(C_{0}\right) / P_{0}} \pi_{t} e^{-\rho t} d t \mid z_{0}\right] \\
& =E\left[\int_{0}^{\infty} \mathbb{I}_{j t} \cdot \frac{P_{0}}{P_{t}} \pi_{t} e^{-\rho t} d t \mid z_{0}\right]
\end{aligned}
$$

where the expectation above is taken over all possible paths for $z_{t}$ and $\mathbb{I}_{j t}$. Non-incumbent firms choose $R_{j}$ to maximize the expected value from a successful innovation net of R\&D costs $\phi R_{j} v_{j}-R_{j}$. It follows that $\phi v_{j} \leq 1$ in equilibrium, with strict equality if $R_{j}>0$. I limit attention to symmetric equilibria in which $R_{j t}$ is the same for all goods $j$, i.e. $R_{j t}=R_{t}$. Since profits $\pi_{t}$ are the same for all intermediate goods, this ensures the value of a successful innovation $v_{j}$ will be the same for all $j$, i.e. $v_{j}=v$. I further limit attention to Markov-perfect equilibria in which $R_{t}$ is constant for a given productivity level $z_{t}$. Such an equilibrium can be summarized by a pair of numbers $\left(R_{0}, R_{1}\right)$. Since this is also true of the optimal path, it seems natural to focus on such equilibria.

I now proceed to express the value of a successful innovation $v$ above strictly in terms of $\left(R_{0}, R_{1}\right)$. To do this, I need to first express the price of final goods $P_{t}$ in terms of $R_{t}$. Since the production of final goods is competitive, the price $P$ equals the minimum cost to produce a single unit of the good in equilibrium, i.e.

$$
\begin{aligned}
P_{t}= & \min _{x_{j t}, K_{t}}\left\{\int_{0}^{1} p_{j t} x_{j t} d j+r_{t} K_{t}\right\} \\
\text { s.t. } & z_{t} K_{t}^{\alpha}\left(\exp \left[\int_{0}^{1} \ln x_{j t} d j\right]\right)^{1-\alpha}=1
\end{aligned}
$$


Using the fact that $p_{j t}=\lambda^{-\left(m_{j t}-1\right)}$ and $r_{t}=\alpha P_{t} Y_{t}$, one can show that

$$
P_{t}=\frac{\lambda\left(L-R_{t}\right)^{\alpha}}{(1-\alpha) z_{t} \lambda^{(1-\alpha) M_{t}}}
$$

Using this, the value of a successful innovation $v_{i}$ if initial productivity $z_{0}=Z_{i}$ is given by

$$
\begin{aligned}
v_{i} & =P_{0} \cdot E\left[\int_{0}^{\infty} \mathbb{I}_{t} \cdot \frac{(\lambda-1)\left(L-R_{t}\right)}{P_{t}} e^{-\rho t} d t \mid z_{0}=Z_{i}\right] \\
& =\text { constant } \times P_{0} \cdot E_{t}\left[\int_{0}^{\infty} \mathbb{I}_{t} \cdot z_{t}\left[\lambda^{M_{t}}\left(L-R_{t}\right)\right]^{1-\alpha} e^{-\rho t} d t \mid z_{0}=Z_{i}\right]
\end{aligned}
$$

Note the similarity between (2.15) and (2.9). The real value an entrepreneur assigns to a successful innovation (after dividing by the price of goods at date 0 ) is proportional to expected discounted output. One can show that the real value a social planner assigns to a successful innovation is likewise proportional to expected discounted output, but as given by (2.9). Since the probability that $\mathbb{I}_{t}=1$ decreases with $t$, i.e. an incumbent is less likely to remain the leader the more time has passed, output produced further in the future is more heavily discounted under (2.15) than under (2.9).

This last observation lies at the heart of why the decentralized economy can fail to optimally substitute over the cycle. Suppose it were optimal to maintain a countercyclical path for innovation, i.e. to set $R_{0}>R_{1}$. This insures output will be higher in booms than in recessions, i.e. $Z_{1}\left(L-R_{1}\right)^{1-\alpha}>Z_{0}\left(L-R_{0}\right)^{1-\alpha}$. At the same time, the fact that $\left\{z_{t}\right\}$ is stationary implies $\lim _{t \rightarrow \infty} E\left[z_{t}\left(L-R_{t}\right)^{1-\alpha} \mid z_{0}=Z_{i}\right]$ does not depend on $Z_{i}$. As we lower the discount rate and give more weight to the future, the expected present discounted value of output given $z_{0}=Z_{0}$ will converge to the expected value given $z_{0}=Z_{1}$ and the ratio $v_{1} / v_{0}$ will fall. Conversely, as we increase the discount rate and give more weight to the present, these two expressions will diverge and the ratio $v_{1} / v_{0}$ will rise. Since private agents discount output more heavily than the social planner, the ratio $v_{1} / v_{0}$ will tend to be higher in the decentralized economy. In response, entrepreneurs will concentrate more of their innovation activity in booms, and equilibrium innovation will exhibit a procyclical bias relative to the social optimum.

Returning to the task of deriving an explicit expression for $v_{i}$, note that for any $z_{t}$-measurable function $X(\cdot)$, the value of the integral

$$
W_{i}\left(M_{0}\right)=E\left[\int_{0}^{\infty} \mathbb{I}_{t} \cdot \lambda^{(1-\alpha) M_{t}} X\left(z_{t}\right) e^{-\rho t} d t \mid z_{0}=Z_{i}\right]
$$

where $\dot{M}_{t}=\phi R_{t}$ can be characterized by the recursive equation

$$
(\rho+\mu) W_{i}(M)=\lambda^{(1-\alpha) M} X\left(Z_{i}\right)+\mu W_{-i}(M)+\left[\frac{\partial W_{i}}{\partial M}-W_{i}(M)\right] \phi R_{i}
$$


The method of undetermined coefficients confirms that $W_{i}(M)=w_{i} \lambda^{(1-\alpha) M}$ such that

$$
w_{i}=\frac{\omega\left(R_{-i}\right) X\left(Z_{i}\right)+\mu X\left(Z_{-i}\right)}{\omega\left(R_{i}\right) \omega\left(R_{-i}\right)-\mu^{2}}
$$

where

$$
\omega(R)=\rho+\mu+(1-(1-\alpha) \ln \lambda) \phi R
$$

The value of a successful innovation $v_{i}$ can therefore be expressed in terms of $R_{0}$ and $R_{1}$, i.e.

$$
v_{i}\left(R_{i}, R_{-i}\right)=(\lambda-1) \frac{\omega\left(R_{-i}\right)\left(L-R_{i}\right)+\mu \frac{Z_{-i}}{Z_{i}}\left(L-R_{-i}\right)^{1-\alpha}\left(L-R_{i}\right)^{\alpha}}{\omega\left(R_{i}\right) \omega\left(R_{-i}\right)-\mu^{2}}
$$

Solving for a symmetric Markov-perfect equilibrium amounts to looking for pairs $\left(R_{0}, R_{1}\right)$ in $[0, L]^{2}$ such that $\phi v_{i}\left(R_{i}, R_{-i}\right) \leq 1$, with strict equality if $R_{i}>0$. The next proposition shows that despite the procyclical bias in equilibrium innovation, $\mathrm{R} \& \mathrm{D}$ is countercyclical. ${ }^{7}$

Proposition 2: Innovation along the equilibrium path is weakly countercyclical in any symmetric Markov-perfect equilibrium, i.e. $R_{0} \geq R_{1}$ along any equilibrium path. Moreover, if $\lambda<e^{\frac{1}{1-\alpha}}$, there exists a unique symmetric Markov-perfect equilibrium.

The fact that equilibrium innovation remains countercyclical is related to my earlier observation that equilibrium profits are just as volatile as the numeraire good, i.e. profits and the cost of $\mathrm{R} \& \mathrm{D}$ fall by the same degree in recessions. In contemplating whether to undertake more innovation, entrepreneurs compare the cost of $R \& D$ not to current profits but to the expected discounted value of all future profits. Since $z_{t}$ is stationary, expected future profits fall less than current profits. Consequently, the discounted value of an innovation will fall by less than the cost of innovation, providing incentive to undertake more innovation in recessions.

Empirically, of course, profits are far more volatile than the cost of R\&D. Mansfield (1987) constructs R\&D price indices between 1969 to 1983 and finds that the R\&D deflator is closely synchronized with the GDP deflator at high frequencies, implying real R\&D costs are not very cyclical. This is not surprising given that nearly half of R\&D expenditures go to labor, and real wages are only mildly procyclical. By contrast, profits are strongly procyclical. The fact that the bias in equilibrium R\&D is not enough to turn it procyclical thus stems from the model's inability to match the high relative volatility of profits we observe in the data. This prompts me to examine what is absent from the preceding analysis that would account for why profits are so highly procyclical in the data.

\footnotetext{
${ }^{7}$ Canton and Uhlig (1999) also prove that equilibrium innovation is countercyclical in a similar model. Aghion and Saint Paul (1998) prove equilibrium innovation is countercyclical in a related model, but they assume only one firm undertakes all innovation, so there is no externality that would lead to a procyclical bias.
} 


\subsection{Fixed Costs and the Volatility of Profits}

An important clue to what the analysis above might be missing is the fact that profits in the model are only as volatile as sales. To wit, the ratio of profits to sales is given by

$$
\frac{\pi_{t}}{e_{t}}=1-\frac{1}{\lambda}
$$

which is constant in the model. But empirically the ratio of aggregate profits to aggregate sales is strongly procyclical, a point emphasized by Ramey (1991). Since empirical evidence suggests that the aggregate markup $\frac{1}{\lambda}$ is either acyclical or moderately countercyclical, Ramey argues that the fact that profits are more volatile than sales points to the presence of some underlying fixed costs of production, i.e. costs that do not vary with sales. Indeed, if producers had to pay some constant amount $F C$, the profit-to-sales ratio would equal

$$
\frac{\pi_{t}}{e_{t}}=\left(1-\frac{1}{\lambda}\right)-\frac{F C}{e_{t}}
$$

which is increasing in $e_{t}$ and can thus be procyclical. In what follows, then, I allow for the possibility that intermediate goods producers incur a fixed cost when producing their goods.

More precisely, producers must face a cost that is fixed with respect to business cycle fluctuations, not just with respect to changes in the amount they produce or sell. To illustrate this distinction, suppose each producer had to hire $\mathcal{K}$ workers to run the firm regardless of how much is produced. By definition, the cost of this labor is fixed with respect to the amount produced. But if real wages are procyclical, this cost will vary with aggregate productivity. In fact, since real wages in the model are just as volatile as sales, the profit-to-sales ratio (2.17) remains constant even with overhead labor. Empirically, real wages are actually less volatile than sales. We could modify the model to accord with this observation as well. ${ }^{8}$ But rather than substantially complicate matters, I pursue an equivalent approach that is more convenient expositionally: I assume that to run the firm, each intermediate-goods producer must purchase $\mathcal{K}$ units of the final good. At the level of the firm, how we specify costs is irrelevant: an individual producer doesn't care whether he has to purchase a fixed number of goods or pay overhead workers a salary equal to this amount. But the way we specify fixed costs does matter at the aggregate level, which requires some care in the way I specify these fixed costs.

\footnotetext{
${ }^{8}$ For example, suppose workers have access to a backyard technology that allows them to produce $b \lambda^{M(1-\alpha)}$ units of output on their own, where $b$ is small but positive. Bargaining frictions that tie down the worker's wage to his outside option would make wages less volatile than sales. For an example of a related R\&D growth model with this type of bargaining friction, see Mortensen (2004).
} 
First, I assume the number of units $\mathcal{K}$ firms purchase grows with the rest of the economy, i.e.

$$
\mathcal{K}_{t}=\lambda^{(1-\alpha) M_{t}} \kappa
$$

for some constant $\kappa$. This assumption is meant to proxy for the fact that when firms hire workers rather than goods, their costs naturally grow with aggregate labor productivity.

Second, I assume that once an incumbent incurs the fixed cost, potential entrants who wish to compete against him can avoid paying it themselves; for example, rather than spend resources recruiting and training workers, an entrant could hire away the incumbent's workers. To see why this assumption is necessary, suppose all producers had to pay the fixed cost. In this case, each additional dollar in fixed costs allows the incumbent to increase his price slightly without the threat of entry, enough to earn an additional $\lambda^{-1}$ dollars. Moreover, each additional dollar in fixed costs increases the equilibrium sales of all producers by a dollar, since final goods producers need to purchase intermediate goods to produce the final goods used to cover fixed costs. This increases equilibrium profits by $1-\lambda^{-1}$ dollars. Thus, for every dollar the firm loses in fixed costs, it gains a dollar in higher gross profits, leaving equilibrium profits unchanged. By contrast, if firms hired a fixed number of workers rather than goods, the amount they spent on fixed costs would have no effect on equilibrium sales, so fixed costs would lower equilibrium profits even when all firms incur such costs. Suppressing the effect of the fixed cost on the price an incumbent can charge only serves to offset the effects of assuming firms purchase goods rather than labor to cover their overhead.

Consider the planner's problem in the presence of these fixed costs. The analog to equation (2.10) is given by

$$
\rho V_{i}(M)=\max _{R \in[0, L]}\left\{\begin{array}{c}
Z_{i}\left[\lambda^{M}(L-R)\right]^{1-\alpha}-\lambda^{(1-\alpha) M} \kappa+ \\
\mu\left(V_{-i}(M)-V_{i}(M)\right)+\frac{\partial V_{i}}{\partial M} \phi R
\end{array}\right\}
$$

The presence of the fixed cost affects the planner's problem, since he would take into account the effect of faster innovation on the fixed cost (as he also would if fixed costs were denominated in units of labor). While this changes the optimal level of innovation, there is no reason it should affect the timing of innovation with respect to $z_{t}$. The next proposition confirms that the optimal path is indeed countercyclical at an interior optimum.

Proposition 3: If (2.8) is satisfied, there exists a unique solution to the social planner's problem. If the optimal path dictates $R_{i}>0$ for all $i$, then optimal innovation must be countercyclical, i.e. $R_{0}>R_{1}>0$. If the optimal path dictates $R_{i}=0$ for some $i$, then the optimal path is guaranteed to be weakly countercyclical, i.e. $R_{0} \geq R_{1}=0$, if $\kappa$ is small. 
Next, I turn to the decentralized economy. Given my assumptions, the incumbent producer of good $j$ will continue to charge the same price as before, $p_{j t}=\lambda^{-\left(m_{j t}-1\right)}$, earning profits

$$
\pi_{j t}=\left(1-\lambda^{-1}\right) e_{t}-P_{t} \mathcal{K}_{t}
$$

Once again, we can express profits directly in terms of $R_{t}$ using the aggregate resource constraint. However, the original constraint in (2.11) must be revised to reflect the fact that the household only purchases those goods that are not used by intermediate goods producers, i.e.

$$
P_{t}\left(Y_{t}-\mathcal{K}_{t}\right)=\Pi_{t}+r_{t} K+L
$$

Substituting this aggregate resource constraint into the expression for profits yields

$$
\pi_{j t}=(\lambda-1)\left(L-R_{t}\right)-P_{t} \mathcal{K}_{t}
$$

instead of (2.12). Solving for the aggregate price $P_{t}$, which turns out to be identical to the expression in (2.14), we obtain the following as the value of a successful innovation:

$$
\begin{aligned}
& v_{i}\left(R_{i}, R_{-i}\right)=(\lambda-1) \frac{\omega\left(R_{-i}\right)\left(L-R_{i}\right)+\mu \frac{Z_{-i}}{Z_{i}}\left(L-R_{-i}\right)^{1-\alpha}\left(L-R_{i}\right)^{\alpha}}{\omega\left(R_{i}\right) \omega\left(R_{-i}\right)-\mu^{2}}- \\
& \frac{\omega\left(R_{-i}\right)+\mu}{\omega\left(R_{i}\right) \omega\left(R_{-i}\right)-\mu^{2}} \frac{\lambda\left(L-R_{i}\right)^{\alpha} \kappa}{(1-\alpha) Z_{i}}
\end{aligned}
$$

Since profits are now more volatile than the cost of the numeraire good, as evident by the presence of $Z_{i}$, we would expect equilibrium R\&D to turn procyclical for a sufficiently large fixed cost. To confirm this conjecture, I begin with the following lemma:

Lemma: Suppose $\lambda<e^{\frac{1}{1-\alpha}}$. Then for any $\kappa>0$, there exists a unique $R^{*}<L$ such that $\phi v_{0}\left(R^{*}, R^{*}\right)=\phi v_{1}\left(R^{*}, R^{*}\right)$. Moreover, there exists a $\kappa^{*}>0$ such that $\phi v_{i}\left(R^{*}, R^{*}\right)<1$ for $\kappa<\kappa^{*}$ and $\phi v_{i}\left(R^{*}, R^{*}\right)>1$ for $\kappa>\kappa^{*}$.

The lemma above establishes that for any fixed cost $\kappa$, there is a unique level of innovation $R^{*}$ that leaves the nominal value of a successful innovation $v$ constant over the cycle. From the proof of the lemma, one can show that this value $v\left(R^{*}, R^{*}\right)$ increases with $\kappa$, ranging from 0 to infinity, so that there must be some $\kappa^{*}$ for which it equals $1 / \phi$. As the next proposition establishes, if $\kappa$ is greater than $\kappa^{*}$, we are assured of finding a pair $\left(R_{0}, R_{1}\right)$ where $R_{1}>R_{0}$ and which satisfies the condition that $\phi v_{i}\left(R_{i}, R_{-i}\right)=1$ for both $i \in\{0,1\}$.

Proposition 4: Suppose $\lambda<e^{\frac{1}{1-\alpha}}$. If $\kappa>\kappa^{*}$, where $\kappa^{*}$ is defined in Lemma 2 , there exists a pair $\left(R_{0}, R_{1}\right)$ where $R_{0}<R_{1}<L$ such that $\phi v_{i}\left(R_{i}, R_{-i}\right)=1$. 
Proposition 4 suggests that for sufficiently large fixed costs, equilibrium innovation will covary positively with productivity. ${ }^{9}$ More precisely, it implies that for sufficiently large fixed costs, we can always find a solution for the system of equations that characterize an interior equilibrium such that $R_{1}>R_{0}$. However, this is not enough to establish either the existence or uniqueness of an equilibrium with procyclical innovation. With regard to existence, Proposition 4 does not guarantee that the solution $\left(R_{0}, R_{1}\right)$ lies in $[0, L]^{2}$ and is hence a proper equilibrium. However, for large enough values of $L$, the solution above appears to lie in $[0, L]^{2}$, mirroring a result in Grossman and Helpman (1991) for the case of no fixed cost. With regard to uniqueness, the set $\left\{\left(R_{0}, R_{1}\right) \mid \phi v_{i}\left(R_{i}, R_{-i}\right)=1\right\}$ can have multiple solutions. However, additional solutions do not appear to correspond to equilibria; rather, they appear to involve high levels of innovation for which the revenue of intermediate goods producers does not cover their fixed costs. For all parameter values I experimented with, the procyclical equilibrium in Proposition 4 remained unique even when more than one solution could be found.

In sum, since the benefits to innovation that pay off in the future are more likely to accrue to someone other than the original innovator, entrepreneurs act short-sightedly and fail to respond optimally to aggregate shocks. This inefficiency is distinct from previous work which has established that long-run growth may be suboptimally too high or too low; the results here concern the relative level of $\mathrm{R} \& \mathrm{D}$ over the cycle rather than the absolute long-run level. For this distortion to account for the procyclicality of $R \& D$, it is important that producers face large fixed costs so that profits are sufficiently volatile over the business cycle. A natural question is whether empirically plausible fixed costs are enough to account for the procyclicality of $\mathrm{R} \& \mathrm{D}$ in the data. To address this question, I first need to relax some of the assumptions above to make the model more amenable to quantitative analysis, a task I take up in the next section.

Since one of these assumptions concerns risk neutrality, it is worth pausing to note that although unrealistic, risk neutrality does serve to illustrate some of the model's more dramatic welfare implications. Consider the welfare effects of aggregate volatility, i.e. the effect of moving from an economy with constant productivity $\bar{Z}$ to one in which $z_{t}$ fluctuates between $Z_{0}$ and $Z_{1}$ but $E\left(z_{t}\right)=\bar{Z}$. In the stable environment, the optimal path mandates a constant level of $R$. Under risk neutrality, the planner can always achieve the same expected utility in the stochastic environment by adopting the same $R$. Proposition 3 then implies that the planner can do strictly better in the volatile environment. By contrast, in the decentralized economy where R\&D can be procyclical, welfare may be lower in the volatile environment. Hence, cyclical

\footnotetext{
${ }^{9}$ One has to be careful about referring to this variation as procyclical, since with procyclical $\mathrm{R} \& \mathrm{D}$ one cannot rule out that output falls when productivity $z$ rises. In all the numerical simulations I tried, output varied positively with productivity.
} 
fluctuations can reduce welfare even when they allow a benevolent planner to achieve a higher level of utility. When I move to a more reasonable utility specification in the next section, the planner will no longer be able to achieve higher utility in the more volatile environment, i.e. business cycles are costly. But it will still be the case that cyclical fluctuations make it more costly to achieve growth even when they allow the planner to achieve growth at a lower overall cost. When I calibrate the model in the next section, I can provide a sense of how much this increase in the cost of growth magnifies the welfare cost of cyclical fluctuations.

\section{Schumpeterian Growth with Concave Utility and Accumulable Capital}

As noted in the previous section, concentrating innovation in recessions lowers the average cost of growth but increases the volatility of output. Under the assumption of risk neutrality, this volatility is inconsequential. However, when the utility function exhibits curvature, the fact that countercyclical innovation increases volatility may make it undesirable. This section therefore modifies the model to allow for concave utility, and examines whether procyclical innovation is still inefficient under empirically plausible assumptions.

In introducing risk aversion, it will be important to also relax the assumption that capital is not accumulable. Otherwise, the only way to smooth consumption over the cycle would be to vary $R \& D$ with productivity, implying procyclical $R \& D$ may in fact be optimal. In practice, though, there are other options to smooth consumption such as inventories and capital accumulation, and since these activities do not occur at the expense of current production, they presumably dominate $\mathrm{R} \& \mathrm{D}$ for purposes of consumption smoothing.

Formally, I modify the model in two ways. First, I replace (2.1) with a more reasonable utility

$$
U\left(C_{t}\right)=\ln C_{t}
$$

With $\log$ utility, there is no longer a need to restrict $\rho$ as in (2.8). Second, I replace the assumption that $K_{t} \equiv 1$ for all $t$ with the assumption that capital satisfies the law of motion

$$
\dot{K}_{t}=I_{t}-\delta K_{t}
$$

where $I_{t}$ denotes investment, i.e. the part of net output that is not consumed by the household, and $\delta$ denotes the depreciation rate for capital. Finally, to ensure that the economy does not outgrow its fixed cost in the presence of capital accumulation, I replace (2.18) with

$$
\mathcal{K}_{t}=\lambda^{M_{t}} \kappa
$$


That is, the economy now grows at the rate $\dot{M} \ln \lambda$ as opposed to $(1-\alpha) \dot{M} \ln \lambda$.

While these modifications are simple to describe, they greatly complicate the analysis by introducing additional state variables. In the next two subsections, I sketch out how to derive the optimal and equilibrium paths of $R$ in this environment. I then solve the model numerically for specific parameter values meant to replicate certain features of U.S. data, and show that the main conclusions from the previous section survive, i.e. equilibrium innovation is inefficiently procyclical at empirically plausible parameter values.

\subsection{The Social Planner's Problem}

I begin with the planner's problem. In lieu of (2.9), the planner's problem is now given by

$$
\begin{gathered}
V_{i}\left(K_{0}, M_{0}\right)=\max _{R_{t}, I_{t}} E\left[\int_{0}^{\infty} \ln \left(z_{t} K_{t}^{\alpha}\left[\lambda^{M_{t}}\left(L-R_{t}\right)\right]^{1-\alpha}-I_{t}-\lambda^{M_{t}} \kappa\right) e^{-\rho t} d t \mid z_{0}=Z_{i}\right] \\
\text { s.t. } \begin{array}{l}
\text { 1. } \dot{M}_{t}=\phi R_{t} \\
\text { 2. } \dot{K}_{t}=I_{t}-\delta K_{t}
\end{array}
\end{gathered}
$$

To solve this problem, I first scale down certain variables by $\lambda^{M}$; specifically, let $k=\lambda^{-M} K$ and $\iota=\lambda^{-M} I$. Using the law of motion for $M$, we can rewrite the above recursively as

$$
\rho v_{i}(k)=\max _{\iota, R}\left\{\begin{array}{c}
\ln \left(Z_{i} k^{\alpha}(L-R)^{1-\alpha}-\iota-\kappa\right)+\frac{\phi R \ln \lambda}{\rho}+ \\
\frac{\partial v_{i}}{\partial k}(\iota-(\delta+\phi R \ln \lambda) k)+\mu\left(v_{-i}(k)-v_{i}(k)\right)
\end{array}\right\}
$$

Combining the two first order conditions for this problem yields the following formula for $R_{i}$, the value of $\mathrm{R} \& \mathrm{D}$ when productivity is equal to $Z_{i}$ :

$$
R_{i}=L-\left[\left(\frac{1}{\rho\left(\partial v_{i} / \partial k\right)}-k\right) \frac{\phi \ln \lambda}{(1-\alpha) Z_{i}^{\alpha} k^{\alpha}}\right]^{-1 / \alpha}
$$

Rather than two numbers $R_{0}$ and $R_{1}$, an optimal plan now corresponds to two functions $R_{0}(k)$ and $R_{1}(k)$. I will refer to a policy as procyclical if it assigns $R_{1}(k)>R_{0}(k)$ for any $k$ in the limiting set of capital-to-productivity ratios for this economy, i.e. for any level of $k$ that occurs infinitely often along the optimal path with probability 1 , and countercyclical if $R_{1}(k)<R_{0}(k)$ for all such $k$. Note that this definition may not correspond to the way R\&D would appear to covary with $z_{t}$ in data generated by this model, since changes in capital accumulation over the cycle may offset the response of $\mathrm{R} \& \mathrm{D}$ to changes in productivity for a fixed $k$. 
To solve for $R_{i}(k)$, we need an expression for the value function $v_{i}(k)$. Since the system in (3.4) does not yield a closed-form solution, I need to solve it numerically. My implementation uses a collocation method whereby I approximate each $v_{i}(k)$ with a polynomial in $k^{10}$

\subsection{Decentralized Equilibrium}

Next, I characterize the equilibrium allocation. Certain features of the equilibrium remain unchanged from the previous section. For example, each intermediate good producer will continue to set his price to the marginal cost of his next most efficient competitor, i.e. $p_{j t}=\lambda^{-\left(m_{j t}-1\right)}$. As such, nominal profits for each producer once again correspond to (2.22). The price of goods $P$ now corresponds to a slightly different expression from (2.14), namely

$$
P=\frac{\lambda^{1-M}(L-R)^{\alpha}}{z(1-\alpha) k^{\alpha}}
$$

As in the previous section, I only consider symmetric equilibria in which innovation is the same across all sectors. To conform with equilibrium, the path for $R$ must satisfy the free entry condition $\phi v=1$, where recall $v$ denotes the expected present discount value of profits to the leading producer,

$$
v=E\left[\int_{0}^{\infty} \mathbb{I}_{t} \cdot \frac{U^{\prime}\left(C_{t}\right) / P_{t}}{U^{\prime}\left(C_{0}\right) / P_{0}} \pi_{t} e^{-\rho t} d t \mid z_{0}\right]
$$

In the previous section, the discount factor applied to profits could be expressed in closed form. But given my new assumptions on preferences and technology, this discount factor no longer admits a simple representation. Thus, rather than back out the path for $R$ directly from the condition that $\phi v=1$, I set out to solve the household maximization problem assuming $\phi v=1$, and then find the path for $R$ that reconciles the optimal solution with this free entry condition.

The household problem amounts to a portfolio allocation problem. At any point in time, the household must decide how to divide its wealth between physical capital and claims on the profits of entrepreneurs. It does this taking as given the distribution of paths of future prices, e.g. the price of capital, the instantaneous return on capital, the profits it expects the entrepreneurs whose claims it might own to earn, and so on. Once it realizes the returns on its investment and earns its labor income, it chooses how much to consume and how much to carry over as wealth to the next instant, when it repeats this decision.

\footnotetext{
${ }^{10}$ More precisely, I obtain an $n$-th order polynomial approximation of each function by choosing $n+1$ coefficients such that when I replace the true $v_{i}(k)$ with the approximate function, (3.4) is exactly satisfied at $n+1$ values of $k$, which are taken to be the roots of the first $n+1$ Chevyshev polynomials adapted to the limiting interval for $k$. The results reported in the paper are based on fourth-order polynomials.
} 
Since the household must hold the claims to all entrepreneurs in equilibrium, it will be convenient to pretend as if there was a mutual fund company that pooled all entrepreneurs into a single portfolio on behalf of the household. Arbitrage requires the value of this portfolio to be the same as the cost of buying up all firms, which is just $\int_{0}^{1} v d j=v$. To insure the fund continues to own all incumbents, it must pay the research expenses of any potential innovator in exchange for the rights to the patent if the innovator is successful, i.e. the fund deducts an operating expense $R$ out of dividends. Thus, the household has the option to pay $v$ for an asset with a dividend of $\Pi=\pi-R$ per unit time, where $\pi$ is given by $(2.20)$.

Let $w$ denote the household's nominal wealth and $\sigma$ denote the fraction of this wealth that the household allocates to capital. The instantaneous change in the household's nominal wealth from its investments in physical capital derives from rental income and capital gains. As long as aggregate productivity remains constant over the next instant, the return per unit of capital is $r+\dot{P}$, and the number of units of capital it holds is $\sigma w / P$. Similarly, the instantaneous change in the household's nominal wealth from investments in the mutual fund derives from fund dividends and capital gains. As long as aggregate productivity $z_{t}$ remains constant, the free entry condition implies $\dot{v}=0$ so there are no capital gains on holding the mutual fund. The return per share of the mutual fund is thus the dividend $\Pi$, and the number of shares it owns is $(1-\sigma) w / v$. On top of the returns to these investments, the household earns labor income which it adds to its wealth and spends some of its wealth on consumption. Thus, as long as $z_{t}$ is constant, $w$ evolves continuous according to the law of motion

$$
\dot{w}=\left[\left(\frac{r}{P}+\frac{\dot{P}}{P}\right) \sigma+\frac{\Pi}{v}(1-\sigma)\right] w+L-\lambda^{M} P c
$$

If instead productivity $z_{t}$ changes discontinuously over the next instant, the wealth of the household in physical capital will jump as the price of capital $P$ jumps discretely with $z$. By contrast, the nominal value of wealth held in the mutual fund will not change since the value of the mutual fund $v=\phi^{-1}$ is independent of aggregate productivity. In this case, the wealth of the household will jump discretely from $w$ to $w^{*}$ where

$$
w^{*}=\left[\frac{P_{-i}}{P_{i}} \sigma+(1-\sigma)\right] w
$$

Let $W$ denote the aggregate wealth of the economy. In equilibrium, $w=W$. However, since individual households act as price takers, they treat the path of $W$ as given and assume it determines the values of all relevant economic variables. As such, solving for an equilibrium amounts to finding a pair of functions $R_{i}(W)$, where the index $i$ reflects the fact that this is the amount of $\mathrm{R} \& \mathrm{D}$ at productivity $Z_{i}$. Given the functions $R_{i}(W)$, we can indeed derive all 
remaining equilibrium quantities. For example, using the fact that $W=P K+v=\lambda^{M} P k+\phi^{-1}$ and the expression for $P$ in $(3.5)$, the capital-to-productivity ratio $k_{i}(W)$ is given by

$$
k_{i}(W)=\left[\frac{\left(W-\phi^{-1}\right) Z_{i}(1-\alpha)}{\lambda\left(L-R_{i}(W)\right)^{\alpha}}\right]^{\frac{1}{1-\alpha}}
$$

Substituting in allows us to obtain the remaining nominal quantities $r, P$, and $\Pi$ as functions of $W$. This implies we can express the household problem recursively in terms of two state variables, $w$ and $W$ :

$$
\rho V_{i}(w, W)=\max _{\sigma, c}\left\{\begin{array}{c}
\ln c+\frac{\phi R \ln \lambda}{\rho}+\frac{\partial V_{i}}{\partial w} \dot{w}+\frac{\partial V_{i}}{\partial W} \dot{W}+ \\
\mu\left(V_{-i}\left(w^{*}, W^{*}\right)-V_{i}(w, W)\right)
\end{array}\right\}
$$

subject to (3.6) and (3.7), as well as the free entry condition $\phi v=1$, and the laws of motion for $W$ which correspond to

$$
\dot{W}=(r+\dot{P}) \lambda^{M} k+\Pi+L-\lambda^{M} P c(W, W)
$$

when $z_{t}$ remains constant over the next instant and a jump to $W^{*}$ if $z_{t}$ changes where

$$
W^{*}=\lambda^{M} P_{-i} k_{i}(W)+\phi^{-1}
$$

The first order conditions for the household problem with respect to $\sigma$ and $c$ are given by

$$
\begin{aligned}
\left(\frac{r}{P}+\frac{\dot{P}}{P}\right)-\phi \Pi & =\mu \frac{\partial V_{-i}\left(w^{*}, W^{*}\right) / \partial w^{*}}{\partial V_{i}(w, W) / \partial w}\left[1-\frac{P_{-i}}{P_{i}}\right] \\
\frac{1}{P c(w, W)} & =\frac{\partial V_{i}}{\partial w}
\end{aligned}
$$

An equilibrium therefore reduces to the set of functions $w_{i}^{*}(w), V_{i}(w, W)$, and $R_{i}(W)$ which satisfy equations (3.7), (3.8), and (3.10).

Again, I can only solve this equilibrium numerically. In particular, I approximate $R_{i}(W)$ and $w_{i}^{*}(w)$ using $n$-th degree polynomials in $W$ and $w$, respectively, and I approximate the function $V_{i}(w, W)$ with the polynomial $\sum_{k=0}^{n} \sum_{\ell=0}^{n-k} a_{k \ell} w^{k} W^{\ell}$. The coefficients of these polynomials are chosen so that the equations above hold exactly at particular values of $(w, W) .{ }^{11}$

\footnotetext{
${ }^{11}$ In particular, consider the set of points $w($ and $W$ ) that correspond to the roots of the Chebyshev polynomials adapted to the limiting interval for $w$. I require equilibrium conditions to be satisfied at $\left\{w_{i}, W_{j}\right\}_{1 \leq i \leq j \leq n+1}$. Note that I need to approximate $V(w, W)$ on and off the equilibrium path to differentiate $\partial V_{i} / \partial w$ from $\partial V_{i} / \partial W$.
} 


\subsection{Calibration and Results}

I now proceed to solve the model for particular parameter values. Since this version of the model corresponds to a standard real business cycle model with an endogenously determined trend growth rate, I can build on previous literature in assigning most of its parameters. The particular values I use are summarized in Table 1.

\begin{tabular}{cccccccccc}
\multicolumn{10}{c}{ Table 1} \\
$\rho$ & 0.05 & $Z_{0}$ & 0.94 & $\mu$ & 0.20 & $\lambda$ & 1.20 & $\kappa$ & 3.6 \\
$\alpha$ & 0.33 & $Z_{1}$ & 1.06 & $\delta$ & 0.08 & $\phi$ & 0.10 & $L$ & 30.8
\end{tabular}

Normalizing a unit of time in the model to correspond to a year, the discount rate $\rho$ is set to $5 \%$. The share of capital in the production of final goods is set to one third. To accord with an unconditional standard deviation of detrended productivity growth of $6 \%$, I set $Z_{0}$ to 0.94 and $Z_{1}$ to 1.06 . The transition rate $\mu$ is set so that the average length of a complete cycle is 10 years, slightly longer than the 8 year frequency often used to identify business cycle fluctuations. The depreciation rate is set to $8 \%$ per year. For $\lambda$, I follow Rotemberg and Woodford (1999) in calibrating the markup to $20 \%$. The productivity term $\phi$ turns out to be a pure scaling parameter, so I normalize it to 0.10 .

The remaining two parameters, $\kappa$ and $L$, are chosen to yield a growth rate of $2 \%$ per year and a share of $\mathrm{R} \& \mathrm{D}$ in output of $2 \%$, in accordance with the average share of total $\mathrm{R} \& \mathrm{D}$ expenditures (private and public, since both can contribute to long-run growth) in GDP. It is not obvious whether the model counterpart to the latter statistic is the share of $R \& D$ in gross output or output net of the amount used by intermediate goods producers to cover fixed cost. However, the difference between the two measures is negligible for small values of $\kappa$; for $\kappa=3.6$, $\mathrm{R} \& \mathrm{D}$ accounts for $2.0 \%$ of gross output and $2.2 \%$ of net output. Simulating the model for these parameter values reveals that the model also generates reasonable time variation in $R \& D$ : the standard deviation of $\mathrm{R} \& \mathrm{D}$ share is $13.9 \%$ and $13.6 \%$ for gross and net output respectively, compared to $13.7 \%$ for total R\&D between 1953 and 2002. However, this period was marked by a steady shift in the composition of R\&D from largely publicly funded in the 1950s to largely privately funded by the 1990s, and it is not obvious that the incentives affecting public R\&D over the business cycle correspond well to those in the model. Certainly the parameter values in Table 1 do not imply implausibly volatile paths for R\&D.

Measured against output, this value of $\kappa$ implies that fixed costs account for $8.1 \%$ of gross output (and $8.8 \%$ of net output). By comparison, Basu (1996), following Ramey (1991), suggests using non-production workers as a proxy for overhead labor. Non-production workers account 
for $20 \%$ of the labor force on average during the post-War period. Since labor accounts for two-thirds of total output, this suggests an even larger overhead cost on the order of $13 \%$ of output, so my value for $\kappa$ is if anything conservative.

Figure 4 plots both optimal and equilibrium $R_{i}(k)$ for the parameter values in Table 1 . In each case, only the limiting set for $k$ is depicted. The arrows indicate the law of motion for capital: capital is decumulated in recessions and accumulated in booms. For the parameter values in Table 1, optimal R\&D policy is countercyclical. However, as more capital is accumulated, labor resources can be freed up to be used for innovation, so some of the countercyclical pattern in $R \& D$ will be undone by changes in the capital stock. Equilibrium R\&D, by contrast, is unambiguously procyclical, even after accounting for more rapid capital accumulation in booms.

Comparing the axes of the two panels in Figure 4 reveals that optimal R\&D is an order of magnitude larger than equilibrium $\mathrm{R} \& \mathrm{D}$. This result mirrors the findings of Jones and Williams (2000), although the wedge between optimal and equilibrium R\&D is much larger here than in their analysis. This is because Jones and Williams allow for diminishing returns to R\&D; with linear returns to $\mathrm{R} \& \mathrm{D}$, the planner would want to devote almost all available labor resources to innovation. As such, the social optimum in this model may be unreliable for carrying out welfare analysis. However, we can still get a sense of the efficiency of procyclical equilibrium R\&D by appealing to perturbation analysis around the non-stochastic steady state, since the effects of small perturbations are insensitive to the degree of curvature in the R\&D sector. Starting with the case where $Z_{0}=Z_{1}=1$ and the corresponding equilibrium $R$, consider a small perturbation of aggregate productivity so that $Z_{0}=1-\varepsilon$ and $Z_{1}=1+\varepsilon$ for $\varepsilon$ small. The key question is how a perturbation from $R$ to $R_{0}=\left(1-\varepsilon^{\prime}\right) R$ and $R_{1}=\left(1+\varepsilon^{\prime}\right) R$ affects welfare in response to a perturbation in productivity. Numerical calculations confirm that this perturbation is welfare reducing for $\varepsilon^{\prime}>0$ and welfare enhancing for $\varepsilon^{\prime}<0$. Thus, the procyclicality of equilibrium R\&D in Figure 4 should indeed be viewed as suboptimal.

To gauge the magnitude of this inefficiency, consider the change in utility when moving from a stable environment where $Z_{0}=Z_{1}=1$ to a volatile environment where $Z_{0} \neq Z_{1}$. In both cases, I evaluate utility starting at the deterministic steady-state level of $k$. Moreover, when $z_{t}$ is stochastic, I evaluate utility at the invariant distribution of $z_{t}$. Following Lucas (1987), we can express the change in utility in terms of the fraction of lifetime consumption agents would be willing to give up to avoid this inefficiency. By a standard Taylor approximation argument, the cost of moving to a volatile environment is proportional to the variance of aggregate productivity $\sigma_{z}^{2}$. For the model as specified, the constant of proportionality turns out to be approximately equal to 1 . We can then decompose this cost into a cost due to volatility in $z_{t}$ holding R\&D 
fixed at its deterministic equilibrium level (but allowing agents to accumulate capital), and a cost due to changes in equilibrium R\&D. For the parameter values in Table 1, the cost of volatility holding $\mathrm{R} \& \mathrm{D}$ fixed is approximately $\frac{1}{3} \sigma_{z}^{2}$. Thus, taking into account the inefficient response of $R \& D$ to aggregate fluctuations fully triples the cost of business cycles relative to models in which the growth rate is treated as exogenous and fixed. Evidently, failing to take into account the endogenous response of growth to cyclical shocks can be quite misleading for welfare analysis. However, rather than contributing to welfare as the Schumpeterian theory would anticipate, the endogenous response of entrepreneurs magnifies the cost of fluctuations.

Of course, since $\sigma_{z}^{2}$ empirically is rather small, the welfare cost of fluctuations remains small even after taking into account the inefficient response of $R \& D$. For example, for a standard deviation of $6 \%$, the cost of fluctuations is $0.36 \%$ of lifetime consumption. This is indeed about three times as large as Lucas' estimated cost of business cycles using direct evidence on consumption (as opposed to calibrating to productivity shocks). However, there is reason to believe that this estimate significantly understates the true cost of the inefficient timing of $R \& D$ over the cycle. This is because the model substantially underpredicts the volatility of trend growth $\phi R \ln \lambda$. The standard deviation of trend growth in the model is about 0.2 percentage points. By contrast, when Barlevy (2004) estimates the volatility of trend growth (i.e. after accounting for changes in the level of economic activity), he finds a standard deviation of 1.8 percentage points. To be sure, not all of this variation is due to R\&D. But the model does appear to generate too little volatility in trend growth relative to what we observe empirically. One reason for this may be that, as is well-known, the preferences used in this paper yield insufficiently volatile asset prices, including the value of a successful innovation $v$ which ultimately drives entrepreneurs to undertake R\&D. Recent work has argued that allowing for time non-separable preferences such as habit-persistence can help to reconcile RBC models with asset prices. Analyzing the model with this class of preferences, as well as allowing for diminishing returns to R\&D as in Jones and Williams (2000), is an important next step for getting a better sense of the true cost of this inefficiency.

Finally, since the fixed cost $\kappa$ plays an essential role, some discussion of the robustness of the results to changes in this parameter are in order. That is, how do the results change as I vary $\kappa$ and adjust $L$ to maintain a steady-state growth rate of $2 \%$ per year? As $\kappa$ is driven to zero, equilibrium innovation indeed turns countercyclical. How large does $\kappa$ have to be for R\&D to be procyclical? For the parameters values in Table 1, the cutoff level above which $R \& D$ is procyclical is approximately 3.3. This corresponds to a fixed cost of about $8.6 \%$ of net output, i.e. fixed costs cannot be much smaller than those I calibrated. For larger values of $\kappa$ than in Table 1, equilibrium R\&D remains procyclical. Moreover, perturbation analysis 
confirms that this procyclical pattern remains inefficient, even for much larger values of $\kappa$. But in contrast to the previous section, the optimal path for $R \& D$ that the planner chooses actually turns procyclical for high values of $\kappa$. Intuitively, increasing $\kappa$ acts in a similar way to increasing the curvature of the utility function, and at the optimal path the planner is essentially so riskaverse that he will even use $R \& D$ to smooth consumption, especially given that the amount of resources devoted to $R \& D$ at the optimal path is so large. But since the equilibrium $R \& D$ share is never much larger than $2 \%$ for reasonable parameter values, there is little to gain from using $\mathrm{R} \& \mathrm{D}$ to smooth consumption, and it remains optimal to concentrate $\mathrm{R} \& \mathrm{D}$ in recessions.

\section{Extensions}

Since the quality-ladder model used to analyze R\&D decisions above abstracts from certain important considerations, this section briefly raises some additional aspects concerning the $\mathrm{R} \& \mathrm{D}$ process and speculates on how they might affect my results.

One feature the model abstracts from is that innovations take time to bring to fruition, so firms should not expect to be able to bring their innovations on-line as soon as aggregate conditions improve. Introducing diffusion lags might make entrepreneurs reluctant to undertake more innovation in booms given they are temporary. Formally, suppose an idea discovered at date $t$ can only be used for production at date $t+T$. By continuity, $R \& D$ will remain procyclical for small $T$. For larger $T$, we would have to explicitly solve the model. This is quite difficult, since the whole continuum of productivity levels $\left[z_{t-T}, z_{t}\right]$ enter as state variables. But intuitively, R\&D should remain procyclical given shocks are persistent. That is, since $\operatorname{Pr}\left(z_{t+T}=z_{t} \mid z_{t}\right)>\operatorname{Pr}\left(z_{t+T} \neq z_{t} \mid z_{t}\right)$, a potential entrant who is constrained to implement his invention only after $T$ units of time should still expect profits at the time of implementation to be higher starting in a boom than in a recession. Diffusion lags mitigate the benefits to procyclical R\&D, but R\&D should still be procyclical for sufficiently large fixed costs.

Another feature the model abstracts from is the possibility that firms strategically delay implementing their innovations, a point raised by Shleifer (1986). This is particularly relevant when aggregate productivity varies over time, since firms can potentially undertake innovation in recessions when the cost of $R \& D$ is low but wait until booms to implement them. While this intuition is suggestive, allowing for strategic delay need not eliminate the inefficient timing of innovation. This is best illustrated using the version of the model in Section 2. The next Proposition provides conditions under which the equilibrium in Proposition 4 survives even when firms can strategically delay implementing their innovations: 
Proposition 5: Suppose $\lambda<e^{1-\alpha}$ and $\frac{\mu}{\rho+\mu}<\frac{Z_{0}}{Z_{1}}$. Then there exists a $\kappa^{\prime}>\kappa^{*}$ as defined in Lemma 2 such that the $\left(R_{0}, R_{1}\right)$ identified in Proposition 4 remains an equilibrium for all $\kappa \in\left(\kappa^{*}, \kappa^{\prime}\right)$ even when agents can implement their technology (and allow rivals to begin research on the next generation) at a different time than when they discover it.

Intuitively, as long as the discount rate $\rho$ is large and regime switches are infrequent so $\mu$ is small, it will not pay to delay innovation until a boom given the long expected wait until it arrives. If the assumptions of Proposition 5 are not satisfied, firms might prefer to delay implementation until aggregate productivity is high, and it is not obvious that the equilibrium identified in Proposition 4 survives. However, even if delayed implementation implies equilibrium R\&D must be countercyclical, innovation would presumably still exhibit a procyclical bias. Moreover, such a model would likely imply that equilibrium implementation is inefficiently procyclical, even if equilibrium innovation is not (since delay is never socially efficient, implementation and innovation should be fully synchronized). The inefficient timing of implementation is related to results in Caballero and Hammour (1996), who show in a different setting that the adoption of new technologies can be distorted in the presence of frictions. Unfortunately, a rigorous analysis of the case of strategic delay in the presence of aggregate fluctuations proves to be quite difficult. While there is work by Francois and Lloyd-Ellis (2003) on strategic delay in quality-ladder models when productivity is fixed, their approach cannot be extended to the case of time-varying productivity.

Another weakness of the model is its failure to match job reallocation over the business cycle. In the model, jobs reallocation occurs when a firm succeeds in innovation and displaces an incumbent. Thus, if equilibrium innovation is procyclical, job reallocation should be as well. But empirically, Davis and Haltiwanger (1992) report that job reallocation is countercyclical, at least in the manufacturing sector. This can potentially be addressed by introducing an additional source of reallocation that is not related to innovation activity. For example, following Young (1998) or Aghion and Saint Paul (1998), we can introduce a "horizontal" variety dimension in addition to the "vertical" quality ladder dimension that is already present in the model. That is, suppose labor is used to produce capital goods, where the number of different capital goods $N$ is endogenous, and these capital goods can in turn be used to produce each of the intermediate good $j \in[0,1]$ as in the model above. If the number of capital goods $N$ decreases with productivity, say because fewer capital goods can be profitably produced at low productivity, recessions will be associated with increased job reallocation to accommodate the smaller variety of capital goods. As long as there were some friction to mitigate job creation, such as search frictions or convex creation costs as in Caballero and Hammour (1996), booms would not 
be associated with a similar burst of job reallocation when variety increases. In this case, a recession would trigger an immediate round of job reallocation, but job reallocation would eventually decline with the decreased rate of creative destruction. This pattern is consistent with recent evidence in Caballero and Hammour (2004) that recessions initially increase job reallocation but lead to a decline in cumulative job reallocation at longer horizons.

\section{Conclusion}

In recent years, economists have argued that recessions encourage agents to seek out more productive uses of resources, and that cycles may even be welfare-improving. Yet one of the main ways in which agents arrive at more productive uses of resources, $R \& D$ effort, appears to be procyclical. This paper provides an explanation for why R\&D might be procyclical even though, as the neo-Schumpeterian view argues, it ought to be concentrated in recessions. Its results reinforce recent work by Caballero and Hammour (2004), who also challenge the prevailing view that recessions promote the reallocation of resources to more productive uses. They argue that cumulative job reallocation is lower rather than higher following recessions, and that this fall in reallocation is costly. This paper focuses on $R \& D$ rather than job reallocation, but it likewise argues that recessions lead to lower rather than higher R\&D activity, and that this decline in $\mathrm{R} \& \mathrm{D}$ is costly. While Schumpeterian theory correctly predicts that recessions ought to act as incubators for productivity growth, frictions - such as the dynamic spillovers outlined in this paper, or the holdup problems emphasized by Caballero and Hammour - preclude recessions from playing this role in practice. ${ }^{12}$

That said, there are papers in the literature - including some of my own work - that argue recessions do in fact promote human capital accumulation and as such contribute to long-run growth. Indeed, Betts and McFarland (1995) and Dellas and Sakellaris (2003) both find that college enrollments are countercyclical, particularly in two-year colleges. ${ }^{13}$ Likewise, Sepulveda (2002) finds that employee training, both on and off-the-job, tends to be countercyclical. This evidence is not inconsistent with the findings of this paper, since R\&D if fundamentally different from human capital accumulation. In particular, while human capital may also involve externalities - e.g. employers might capture some of the returns to human capital if the wage

\footnotetext{
${ }^{12}$ Relatedly, Barlevy (2002) argues search frictions prevent recessions from allocating resources to their best uses, even though they should ameliorate productive inefficiency by cleansing less productive uses of resources.

${ }^{13}$ By contrast, King and Sweetman (2002) argue the number of workers who quit their job to return to school is procyclical. But committing to school full-time is a special form of human capital accumulation, and may be risky in recessions when job openings are scarce. Indeed, part-time college enrollment is countercyclical.
} 
distribution is somehow compressed - there is no comparable sense in which these externalities are greater the more time that has passed since the worker acquired his skills. The fact that an activity whose opportunity cost is also lower in recessions but is not subject to the same distortions as $\mathrm{R} \& \mathrm{D}$ is concentrated in downturns accords with the view that, absent distortions, $\mathrm{R} \& \mathrm{D}$ would likely be countercyclical.

The inefficient response of R\&D to cyclical fluctuations outlined here suggests a new cost of business cycles beyond the costs already noted in previous literature. It is certainly distinct from the cost of volatility due to risk-aversion as emphasized in Lucas (1987) and subsequent work that builds on his original insights. It is also distinct from previous work that argues cycles are costly because of their effect on growth, e.g. Barlevy (2004), since here the effect involves the timing of innovation rather than the level of innovation. The quantitative analysis above suggests that this inefficient timing triples the cost of business cycles relative to models in which growth is assumed to be unaffected by cyclical fluctuations. This is more modest than the costs cycles impose because of their effect on the level of growth as reported in Barlevy (2004); however, the estimated cost in this paper is likely to be understated given that trend growth is more volatile than implied by the model. But even if the cost is much larger, it does not necessarily follow that stabilization is desirable, since policymakers could always avoid this cost by subsidizing R\&D during recessions. In fact, since volatility may allow the economy to grow at a lower overall cost, it may be distinctly undesirable to eliminate fluctuations, especially for low degrees of risk aversion.

While this paper focuses primarily on cyclical fluctuations, it also contributes to the literature on long-run growth. Whereas most of this literature only considers steady-state growth, this paper tackles the more difficult case of non-steady-state dynamics. It reveals that spillovers inherent to the $R \& D$ process can lead the economy to respond inefficiently to shocks around the steady state, independently of whether the steady-state level is too high or too low. As such, it suggests that inefficient growth is more pervasive than even previous work would suggest, since even when the long-run steady state growth is efficient, i.e. the absolute level of innovation is optimal, it might still be the case that the relative levels of innovation over time are suboptimal. To put it another way, there may be scope for policymakers to intervene in the market for R\&D even when an analysis based only on steady-state comparisons would suggest a minimal role for intervention. 


\section{Appendix}

Proof of Propositions 1 and 3: For given values $R_{0}$ and $R_{1}$, the system given by $(2.10)$ reduces to ordinary linear differential equations in $V\left(Z_{i}, M\right)$. Standard theorems ensure this system has a unique solution. Hence, for any conjectured values of $R_{i}$, we can use the method of undetermined coefficients to find the unique value functions $V\left(Z_{i}, M\right)$ associated with a given pair $\left(R_{0}, R_{1}\right)$. I conjecture that the value function $V(\cdot, \cdot)$ takes the form

$$
V\left(Z_{i}, M\right)=v_{i} \lambda^{M(1-\alpha)}
$$

Differentiating this function with respect to $M$ yields

$$
\frac{\partial V}{\partial M}=(1-\alpha) v_{i} \lambda^{M(1-\alpha)} \ln \lambda
$$

which simplifies the differential equations above to a system of independent linear equations in the coefficients $v_{i}$ :

$$
\rho v_{i}=Z_{i}\left(L-R_{i}\right)^{1-\alpha}-\kappa+\mu\left(v_{-i}-v_{i}\right)+(1-\alpha) v_{i} \phi R_{i} \ln \lambda
$$

This yields a unique solution $\left(v_{0}, v_{1}\right)$ for any pair $\left(R_{0}, R_{1}\right)$.

Since the RHS of (2.10) is strictly concave in $R_{i}$, the first order condition is both necessary and sufficient to characterize the optimal $R_{i}$. The first order condition is given by

$$
-(1-\alpha) Z_{i} \lambda^{M(1-\alpha)}\left(L-R_{i}\right)^{-\alpha}+\frac{\partial V}{\partial M} \phi \leq 0
$$

with equality if $R_{i}>0$. These first order conditions confirm that an optimal policy reduces to a pair of numbers $\left(R_{0}, R_{1}\right)$, so we can proceed to assume $V\left(Z_{i}, M\right)=v_{i} \lambda^{M(1-\alpha)}$. This implies

$$
R_{i}=\left\{\begin{array}{cl}
L-\left(\frac{Z_{i}}{v_{i} \phi \ln \lambda}\right)^{\frac{1}{\alpha}} & \text { if } v_{i}>\frac{Z_{i}}{\phi L^{\alpha} \ln \lambda} \\
0 & \text { else }
\end{array}\right.
$$

If we substitute this expression into the asset equation (2.10), we obtain a pair of equations with $v_{-i}$ as a function of $v_{i}$ that hold at the optimal $R_{i}$ :

$$
v_{-i}=f_{-i}\left(v_{i}\right) \equiv \begin{cases}\frac{(\rho+\mu-(1-\alpha) \phi L \ln \lambda)}{\mu} v_{i}-\frac{\alpha}{\mu} Z_{i}^{\frac{1}{\alpha}}\left(v_{i} \phi \ln \lambda\right)^{1-\frac{1}{\alpha}}+\frac{\kappa}{\mu} & \text { if } v_{i}>\frac{Z_{i}}{\phi L^{\alpha} \ln \lambda} \\ \frac{\rho+\mu}{\mu} v_{i}-\frac{Z_{i} L^{1-\alpha}}{\mu}+\frac{\kappa}{\mu} & \text { else }\end{cases}
$$

The optimal program corresponds to any pair $\left(v_{0}^{*}, v_{1}^{*}\right)$ which solves the equations

$$
\begin{aligned}
& v_{1}^{*}=f_{1}\left(v_{0}^{*}\right) \\
& v_{0}^{*}=f_{0}\left(v_{1}^{*}\right)
\end{aligned}
$$

The function $f_{-i}(\cdot)$ is continuous and differentiable, since the left and right hand derivatives at $v_{i}=\frac{Z_{i}}{\phi L^{\alpha} \ln \lambda}$ are both equal to $\frac{\rho+\mu}{\mu}$. Since $\rho>(1-\alpha) \phi L \ln \lambda$, it follows that $\frac{\partial f_{-i}\left(v_{i}\right)}{\partial v_{i}}>1$ for all $v_{i}$. The functions $f_{-i}(\cdot)$ are illustrated in Figure A1, suggesting that there is a unique solution $\left(v_{0}^{*}, v_{1}^{*}\right)$. 
To establish this formally, I use the fact that since $\frac{d f_{-i}}{d v_{i}}>0$ for all $v_{i}, f_{-i}(\cdot)$ must be invertible. An equilibrium thus corresponds to a value $v_{0}^{*}$ such that $f_{1}\left(v_{0}^{*}\right)-f_{0}^{-1}\left(v_{0}^{*}\right)=0$. Differentiating this condition with respect to $v_{0}^{*}$ yields

$$
\frac{d}{d x}\left[f_{1}(x)-f_{0}^{-1}(x)\right]=\frac{d f_{1}}{d x}-\left(\frac{d f_{0}}{d x}\right)^{-1}>0
$$

This monotonicity insures there is at most one equilibrium $v_{0}^{*}$. To establish existence, note that $f_{1}(0)<0$ while $f_{0}^{-1}(0)>0$. Hence, $f_{1}(0)-f_{0}^{-1}(0)<0$, and is finite. The fact that $\lim _{x \rightarrow \infty} \frac{d f_{1}}{d x}>1>\lim _{x \rightarrow \infty}\left(\frac{d f_{0}}{d x}\right)^{-1}$ implies $\frac{\partial}{\partial x}\left[f_{1}(x)-f_{0}^{-1}(x)\right]$ is strictly bounded away from 0 , and so $f_{1}(x)-f_{0}^{-1}(x) \rightarrow \infty$ as $x \rightarrow \infty$. The existence of $v_{0}^{*}$ follows from continuity. This implies there is a unique social solution to the social planner's problem.

Next, I need to show that if at the optimum $R_{i}>0$ for both $i$, then $R_{0}>R_{1}$. The proof proceeds in two steps. First, I argue that $v_{1}^{*}>v_{0}^{*}$. Since $R_{i}>0$, the asset equations imply

$$
\begin{aligned}
v_{-i}^{*} & =\frac{(\rho+\mu-(1-\alpha) \phi L \ln \lambda)}{\mu} v_{i}^{*}-\frac{\alpha}{\mu} Z_{i}^{\frac{1}{\alpha}}\left(v_{i}^{*} \phi \ln \lambda\right)^{1-\frac{1}{\alpha}}+\frac{\kappa}{\mu} \\
& \equiv a v_{i}^{*}-b Z_{i}^{\frac{1}{\alpha}}\left(v_{i}^{*}\right)^{1-\frac{1}{\alpha}}+\frac{\kappa}{\mu}
\end{aligned}
$$

Consider the value $\widehat{v}_{i}$ which solves

$$
\widehat{v}_{i}=a \widehat{v}_{i}-b Z_{i}^{\frac{1}{\alpha}}\left(\widehat{v}_{i}\right)^{1-\frac{1}{\alpha}}+\frac{\kappa}{\mu}
$$

It is easy to show $\widehat{v}_{i}$ exists and is unique. Implicit differentiation implies

$$
\frac{d \widehat{v}_{i}}{d Z_{i}}=\frac{\frac{b}{\alpha}\left(\frac{\widehat{v}_{i}}{Z_{i}}\right)^{1-\frac{1}{\alpha}}}{(\alpha-1)+\frac{1-\alpha}{\alpha} b\left(\frac{Z_{i}}{\widehat{v}_{i}}\right)^{\frac{1}{\alpha}}}>0
$$

so that $Z_{0}<Z_{1} \Rightarrow \widehat{v}_{0}<\widehat{v}_{1}$. Since $\frac{d f_{i}^{-1}}{d x}<1$, we know that for any $x<\widehat{v}_{1}$, it must be the case that $x-f_{0}^{-1}(x)<0$. Hence,

$$
\begin{aligned}
f_{1}\left(\widehat{v}_{0}\right)-f_{0}^{-1}\left(\widehat{v}_{0}\right) & =\widehat{v}_{0}-f_{0}^{-1}\left(\widehat{v}_{0}\right) \\
& <0
\end{aligned}
$$

where the inequality uses the fact that $\widehat{v}_{0}>\widehat{v}_{1}$. Since $f_{1}\left(v_{0}^{*}\right)-f_{0}^{-1}\left(v_{0}^{*}\right)=0$ and $f_{1}(x)-f_{0}^{-1}(x)$ is increasing in $x$, it follows that $v_{0}^{*}>\widehat{v}_{0}$. But since $\frac{d f_{i}^{-1}}{d x}>1$, the fact that $f_{1}\left(\widehat{v}_{0}\right)=\widehat{v}_{0}$ implies $f_{1}(x)>x$ for any $x>\widehat{v}_{0}$. Hence, $f_{1}\left(v_{0}^{*}\right)>v_{0}^{*}$. But since $v_{1}^{*}=f_{1}\left(v_{0}^{*}\right)$, it follows that $v_{1}^{*}>v_{0}^{*}$.

Next, I use the fact that $v_{1}^{*}>v_{0}^{*}$ to argue $\frac{v_{1}^{*}}{Z_{1}}<\frac{v_{0}^{*}}{Z_{0}}$, which is sufficient to establish $R_{1}<R_{0}$ from the first-order condition above. Since $v_{-i}^{*}-f_{-i}\left(v_{i}^{*}\right)=v_{i}^{*}-f_{i}\left(v_{-i}^{*}\right)=0$, we have

$$
a v_{0}^{*}-b Z_{0}^{\frac{1}{\alpha}}\left(v_{0}^{*}\right)^{1-\frac{1}{\alpha}}-v_{1}^{*}=a v_{1}^{*}-b Z_{1}^{\frac{1}{\alpha}}\left(v_{1}^{*}\right)^{1-\frac{1}{\alpha}}-v_{0}^{*}
$$


which can be rearranged to yield

so that

$$
\frac{v_{0}^{*}}{v_{1}^{*}}=\frac{(a+1)-b\left(\frac{Z_{1}}{v_{1}^{*}}\right)^{\frac{1}{\alpha}}}{(a+1)-b\left(\frac{Z_{0}}{v_{0}^{*}}\right)^{\frac{1}{\alpha}}}
$$

$$
v_{1}^{*}>v_{0}^{*} \Leftrightarrow \frac{v_{1}^{*}}{v_{0}^{*}}<\frac{Z_{1}}{Z_{0}}
$$

But given the expression for $R_{i}$ in (5.2), this implies $R_{0}>R_{1}$.

Finally, suppose $R_{i}=0$ for some $i$. The proposition follows if we can rule out the case where $R_{0}=0$ and $R_{1}>0$ for sufficiently small $\kappa$. Once again, it will be enough to show that $\frac{v_{1}^{*}}{v_{0}^{*}}<\frac{Z_{1}}{Z_{0}}$. Let $v_{i}^{*}\left(Z_{0}, Z_{1}\right)$ denote the values of $v_{i}^{*}$ given $Z_{0}$ and $Z_{1}$. It will be enough to prove that

$$
\frac{\partial}{\partial Z_{1}}\left[\frac{Z_{0} v_{1}^{*}\left(Z_{0}, Z_{1}\right)}{Z_{1} v_{0}^{*}\left(Z_{0}, Z_{1}\right)}\right]<0
$$

This is because by integrating (5.3) with respect to $Z_{1}$, we obtain

$$
\begin{aligned}
\frac{Z_{0} v_{1}^{*}\left(Z_{0}, Z_{1}\right)}{Z_{1} v_{0}^{*}\left(Z_{0}, Z_{1}\right)} & =\left[\frac{Z_{0} v_{1}^{*}\left(Z_{0}, Z_{0}\right)}{Z_{0} v_{0}^{*}\left(Z_{0}, Z_{0}\right)}\right]+\int_{Z_{0}}^{Z_{1}} \frac{\partial}{\partial Z_{1}}\left[\frac{Z_{0} v_{1}^{*}\left(Z_{0}, Z_{1}\right)}{Z_{1} v_{0}^{*}\left(Z_{0}, Z_{1}\right)}\right] d Z_{1} \\
& <\left[\frac{Z_{0} v_{1}^{*}\left(Z_{0}, Z_{0}\right)}{Z_{0} v_{0}^{*}\left(Z_{0}, Z_{0}\right)}\right]=1
\end{aligned}
$$

Note that (5.3) holds if and only if

$$
\frac{\partial}{\partial Z_{1}} \ln \left(\frac{Z_{0} v_{1}^{*}\left(Z_{0}, Z_{1}\right)}{Z_{1} v_{0}^{*}\left(Z_{0}, Z_{1}\right)}\right)<0
$$

or alternatively if

$$
\frac{\partial v_{1}^{*} / \partial Z_{1}}{v_{1}^{*} / Z_{1}}<1+\frac{\partial v_{0}^{*} / \partial Z_{1}}{v_{0}^{*} / Z_{1}}
$$

Differentiating the asset equations with respect to $Z_{1}$ yields

$$
\begin{aligned}
\frac{\partial v_{1}}{\partial Z_{1}} & =\left\{\begin{array}{cc}
\frac{\left(L-R_{1}\right) \phi \ln \lambda}{\phi\left(L-R_{1}\right) \ln \lambda+\alpha \phi R_{1} \ln \lambda} \frac{v_{1}}{Z_{1}} & \text { if } R_{1}>0 \\
\frac{(\rho+\mu) Z_{0} L^{1-\alpha}}{(\rho+\mu) Z_{1} L^{1-\alpha}+\mu\left(Z_{0} L^{1-\alpha}+A\right)-(\rho+2 \mu) \kappa} \frac{v_{1}}{Z_{1}} & \text { if } R_{1}=0
\end{array}\right. \\
\frac{\partial v_{0}}{\partial Z_{1}} & =\frac{\mu}{\rho+\mu-(1-\alpha) \phi R_{-i} \ln \lambda} \frac{\partial v_{1}}{\partial Z_{1}}
\end{aligned}
$$

where $A$ is defined by

$$
Z_{0} L^{1-\alpha}+A=\max _{R_{0}}\left\{Z_{0}\left(L-R_{0}\right)^{1-\alpha}+(1-\alpha) v_{0} \phi R_{0} \ln \lambda\right\}
$$

so that $A \geq 0$. If $\kappa<\frac{\mu}{\rho+2 \mu} Z_{0} L^{1-\alpha}$, then $\frac{\partial v_{1}}{\partial Z_{1}}<\frac{v_{1}}{Z_{1}}$ and $\frac{\partial v_{0}}{\partial Z_{1}}>0$. This insures $\frac{\partial v_{1}^{*} / \partial Z_{1}}{v_{1}^{*} / Z_{1}}<1<$ $1+\frac{\partial v_{0}^{*} / \partial Z_{1}}{v_{0}^{*} / Z_{1}}$, completing the proof. 
Lemma 1: Let $h(\xi)=\frac{\mu}{\omega(L)}\left[\frac{Z_{1}}{Z_{0}} \xi^{\alpha}-\frac{Z_{0}}{Z_{1}} \xi^{1-\alpha}\right]$, where $\omega(L)=\rho+\mu+(1-(1-\alpha) \ln \lambda) \phi L$. There exists a unique $\xi^{*}>0$ such that $1-\xi^{*} \gtreqless h\left(\xi^{*}\right)$ if $\xi \lesseqgtr \xi^{*}$. This unique solution $\xi^{*}$ lies in the interval $(0,1)$.

Proof of Lemma 1: First, I claim there exists a $\xi^{*} \in(0,1)$ for which $1-\xi=h(\xi)$. This is straightforward: if $\xi=0$, we have

$$
1-\xi=1>0=h(\xi)
$$

while if $\xi=1$, we have

$$
1-\xi=0<\frac{\mu}{\omega(L)}\left[\frac{Z_{1}}{Z_{0}}-\frac{Z_{0}}{Z_{1}}\right]=h(\xi)
$$

where the inequality relies on the fact that $\omega(L)>0$ given that $\rho>(1-\alpha) \phi L \ln \lambda$. The claim follows from continuity.

To prove $\xi^{*}$ is unique, I proceed in two steps. First, differentiating $h(\cdot)$ yields

$$
h^{\prime}(\xi)=\frac{\mu}{\omega(L)}\left[\alpha \frac{Z_{1}}{Z_{0}} \xi^{\alpha-1}-(1-\alpha) \frac{Z_{0}}{Z_{1}} \xi^{-\alpha}\right]
$$

For $\xi \geq 1$, we have

$$
\begin{aligned}
\alpha \frac{Z_{1}}{Z_{0}} \xi^{\alpha-1}-(1-\alpha) \frac{Z_{0}}{Z_{1}} \xi^{-\alpha} & >-(1-\alpha) \frac{Z_{0}}{Z_{1}} \xi^{-\alpha} \\
& >-1
\end{aligned}
$$

Since $h(\xi)>1-\xi$ at at $\xi=1$, a necessary condition for there to exist a $\xi^{*}>1$ such that $1-\xi^{*}=h\left(\xi^{*}\right)$ is that there exists a $\xi>1$ such that $h^{\prime}(\xi)<-1$. Thus, there exists no $\xi>1$ for which $1-\xi=h(\xi)$.

Next, I need to show there is a unique $\xi^{*} \in(0,1)$ for which $1-\xi^{*}=h\left(\xi^{*}\right)$. Consider first the case where $\alpha>\frac{1}{2}$. Differentiating $h(\cdot)$ establishes that $h^{\prime}(\xi) \geq 0$ if and only if

$$
\frac{\alpha}{1-\alpha}\left(\frac{Z_{1}}{Z_{0}}\right)^{2}>\xi^{1-2 \alpha}
$$

For $\alpha>\frac{1}{2}, 1-2 \alpha<0$, and so $h^{\prime}(\xi)$ is negative if $0<\xi<\left[\frac{\alpha}{1-\alpha}\left(\frac{Z_{1}}{Z_{0}}\right)^{2}\right]^{\frac{1}{1-2 \alpha}}$ and positive if $\xi>\left[\frac{\alpha}{1-\alpha}\left(\frac{Z_{1}}{Z_{0}}\right)^{2}\right]^{\frac{1}{1-2 \alpha}}$. Since $h(0)=0$, it follows that $h(\xi)<0$ for $0<\xi<\left[\frac{\alpha}{1-\alpha}\left(\frac{Z_{1}}{Z_{0}}\right)^{2}\right]^{\frac{1}{1-2 \alpha}}$. Hence, $1-\xi>0>h(\xi)$ for $\xi<\left[\frac{\alpha}{1-\alpha}\left(\frac{Z_{1}}{Z_{0}}\right)^{2}\right]^{\frac{1}{1-2 \alpha}}<1$. The fact that $h^{\prime}(\xi)$ is strictly positive for $\xi>\left[\frac{\alpha}{1-\alpha}\left(\frac{Z_{1}}{Z_{0}}\right)^{2}\right]^{\frac{1}{1-2 \alpha}}$ insures that $\xi^{*}$ is unique and that $1-\xi^{*} \gtreqless h\left(\xi^{*}\right)$ if $\xi \lesseqgtr \xi^{*}$

If $\alpha=\frac{1}{2}, h(\xi)$ simplifies to $\frac{\mu}{\omega(L)}\left[\frac{Z_{1}-Z_{0}}{Z_{1} Z_{0}}\right] \xi^{\frac{1}{2}}$ which is monotonically increasing in $\xi$ while $1-\xi$ is monotonically decreasing. This again insures $\xi^{*}$ is unique and $1-\xi^{*} \gtreqless h\left(\xi^{*}\right)$ if $\xi \lesseqgtr \xi^{*}$ 
Finally, if $\alpha<\frac{1}{2}$, we can establish uniqueness by showing that $h^{\prime}(\xi)>-1$ for all $\xi \in(0,1]$. Differentiating $h(\cdot)$ twice yields

$$
h^{\prime \prime}(\xi)=\frac{\alpha(1-\alpha) \mu}{\omega(L)}\left[\frac{Z_{0}}{Z_{1}} \xi^{-\alpha-1}-\frac{Z_{1}}{Z_{0}} \xi^{\alpha-2}\right]
$$

so that

$$
h^{\prime \prime}(\xi) \gtreqless 0 \Leftrightarrow \xi \gtreqless\left(\frac{Z_{1}}{Z_{0}}\right)^{\frac{2}{1-2 \alpha}}
$$

Thus, the derivative attains a minimum at $\xi=\left(\frac{Z_{1}}{Z_{0}}\right)^{\frac{2}{1-2 \alpha}}$ which for $\alpha<\frac{1}{2}$ is strictly greater than 1 . But it was previously argued that $h^{\prime}(\xi)>-1$ for all $\xi \geq 1$. Hence, $h^{\prime}(\xi)>-1$ for all $\xi \in(0, \infty)$ if $\alpha<\frac{1}{2}$.

Lastly, since at $\xi=0,1-\xi=1>0=h(\xi)$, continuity implies $1-\xi>h(\xi)$ for all $\xi<\xi^{*}$. Likewise, at $\xi=1,1-\xi=0<h(1)$, so by continuity it follows that $1-\xi<h(\xi)$ for $\xi>\xi^{*}$. This establishes the lemma.

Proof of Proposition 2: Since $R_{i} \geq 0$, the case where $R_{1}=0$ trivially satisfies the claim. If $R_{0}=0$, we need to verify that $R_{1}=0$. To show this, suppose not, i.e. suppose $R_{1}>0=R_{0}$. Then it follows that $\phi v_{1}=1 \geq \phi v_{0}$. Substituting in for $v_{i}$, we get

$$
\left\{\begin{array}{l}
\omega\left(R_{0}\right)\left(L-R_{1}\right)+ \\
\mu \frac{Z_{0}}{Z_{1}}\left(L-R_{0}\right)^{1-\alpha}\left(L-R_{1}\right)^{\alpha}
\end{array}\right\} \geq\left\{\begin{array}{l}
\omega\left(R_{1}\right)\left(L-R_{0}\right)+ \\
\mu \frac{Z_{1}}{Z_{0}}\left(L-R_{1}\right)^{1-\alpha}\left(L-R_{0}\right)^{\alpha}
\end{array}\right\}
$$

Since $v_{1}\left(R_{1}, R_{0}\right)=0$ if $R_{1}=L$, then $R_{1}<L$ in any such equilibrium. This allows us to define $\xi$ such that

$$
R_{0}=\xi R_{1}+(1-\xi) L
$$

Note that since $R_{1}<L$, by construction, $\xi \geq 0$, and $R_{0}>R_{1}$ implies $\xi \in[0,1)$ while $R_{0}<R_{1}$ implies $\xi>1$. After substituting in for $\omega(R)$ and rewriting $R_{0}$ in terms of $R_{1}$, we can rewrite the inequality $v_{1} \geq v_{0}$ in terms of $\xi$ :

$$
1-\xi \geq \frac{\mu}{\omega(L)}\left[\frac{Z_{1}}{Z_{0}} \xi^{\alpha}-\frac{Z_{0}}{Z_{1}} \xi^{1-\alpha}\right]
$$

Applying lemma 1, it follows that $\xi<\xi^{*}<1$, which implies $R_{0}>R_{1}$, a contradiction. Thus, $R_{0}=0$ implies $R_{1}=0$.

Finally, if $R_{1}$ and $R_{0}$ are both positive, it must be true that $v_{1}=v_{0}=\frac{1}{\phi}$, so once again we can define $R_{0}=\xi R_{1}+(1-\xi) L$ which in turn implies that $1-\xi=h(\xi)$. But from the lemma, the unique $\xi^{*}$ which satisfies this equation is less than 1 , which implies $R_{0} \geq R_{1}$.

Next, I show that there exists a unique symmetric Markov-perfect equilibrium when $\lambda<e^{\frac{1}{1-\alpha}}$. This condition implies that $(1-\alpha) \ln \lambda<1$, which implies

$$
\omega^{\prime}(R)=(1-(1-\alpha) \ln \lambda) \phi>0
$$

Using (2.16), the fact that $\omega^{\prime}(R)>0$ can be shown to imply that $\frac{\partial v_{i}}{\partial R_{i}}<0$ and $\frac{\partial v_{i}}{\partial R_{-i}}<0$. Recall from the proof of Proposition 2 that in any Markov-perfect equilibrium in which $\phi v_{i}\left(R_{i}, R_{-i}\right)=1$ for 
both $i$, the levels of innovation for the two levels of productivity are related by $R_{0}=\xi^{*} R_{1}+\left(1-\xi^{*}\right) L$, where $\xi^{*}$ is a constant. Hence, there can be at most one equilibrium in which $\phi v_{0}=\phi v_{1}=1$. For suppose there were two such equilibria, $\left(R_{0}, R_{1}\right) \neq\left(R_{0}^{\prime}, R_{1}^{\prime}\right)$ where wlog $R_{0}^{\prime}>R_{0}$. Since $\xi^{*}$ is constant, it follows that $R_{1}^{\prime}>R_{1}$, but since $v_{i}$ is decreasing in both $R_{i}$ and $R_{-i}$ it is impossible that $v_{i}\left(R_{i}, R_{-i}\right)=$ $v_{i}\left(R_{i}^{\prime}, R_{-i}^{\prime}\right)=\frac{1}{\phi}$.

If $\left(R_{0}, R_{1}\right)=(0,0)$ is an equilibrium, given that $\frac{\partial v_{i}}{\partial R_{i}}<0$, it follows that for any $\left(R_{0}, R_{1}\right) \neq 0$ there always exists some $i \in\{0,1\}$ such that $\phi v_{i}<1$ but $R_{i}>0$, which is inconsistent with equilibrium. In this case, $(0,0)$ would be the unique equilibrium. Without loss of generality, then, I henceforth assume that if an equilibrium exists, it is not equal to $(0,0)$.

I begin by arguing that if there exists an equilibrium $\left(R_{0}^{*}, R_{1}^{*}\right)$ where $\phi v_{i}\left(R_{i}^{*}, R_{-i}^{*}\right)=1$ for both $i$, there exists no other equilibria in which $R_{i}=0$ and $\phi v_{i}\left(0, R_{-i}\right)<1$ for some $i \in\{0,1\}$. For each $i$, define the contour sets

$$
{ }_{i}=\left\{\left(R_{i}, R_{-i}\right) \mid \phi v_{i}\left(R_{i}, R_{-i}\right)=1\right\}
$$

for all values of $\left(R_{0}, R_{1}\right) \geq(0,0)$. These sets are illustrated in Figure A2. Using the implicit function theorem and the fact that $\frac{\partial v_{i}}{\partial R_{i}}$ and $\frac{\partial v_{i}}{\partial R_{-i}}$ are both strictly negative, we can establish that the graphs of ${ }_{i}$ form connected, downward sloping curves in $\left(R_{0}, R_{1}\right)$ space. If there exists an equilibrium $\left(R_{0}^{*}, R_{1}^{*}\right) \neq$ $(0,0)$ such that $\phi v_{i}\left(R_{i}^{*}, R_{-i}^{*}\right)=1$ for both $i$, the sets $i$ must both be nonempty. Since $\frac{\partial v_{i}}{\partial R_{-i}}<0$ and $\phi v_{i}\left(R_{i}^{*}, R_{-i}^{*}\right)=1$, then $\phi v_{i}\left(R_{i}^{*}, 0\right)>1$. Since $\phi v_{i}(L, 0)=0$, there exists an $R_{i}^{\prime} \geq 0$ such that $\left(R_{i}^{\prime}, 0\right) \in \quad{ }_{i}$ by continuity. Hence, The graph of ${ }_{i}$ intersects the $R_{i}$ axis.

Next, define $R_{-i}^{\prime \prime}>0$ as the value of $R_{-i}$ such that $\phi v_{i}\left(0, R_{-i}^{\prime \prime}\right)=1$. If no such value exists, I adopt the convention that $R_{-i}^{\prime \prime}=\infty$. I now argue that $R_{1}^{\prime \prime}>R_{1}^{\prime}$. The statement follows trivially if $R_{1}^{\prime \prime}=\infty$. If $R_{1}^{\prime \prime}<\infty$, I argue that $\phi v_{1}\left(R_{1}^{\prime \prime}, 0\right)>1$. For suppose not, i.e. suppose $\phi v_{1}\left(R_{1}^{\prime \prime}, 0\right) \leq 1$. Since $\phi v_{0}\left(0, R_{1}^{\prime \prime}\right)=$ 1 , it follows that either $\left(0, R_{1}^{\prime \prime}\right)$ constitutes an equilibrium, or there exists some $R_{1}^{\prime \prime \prime} \in\left(R_{1}^{\prime \prime}, L\right)$ such that $\phi v_{1}\left(R_{1}^{\prime \prime \prime}, 0\right)=1$, from which it follows that $\left(0, R_{1}^{\prime \prime \prime}\right)$ is an equilibrium. Since $R_{0} \geq R_{1}$ in any Markovperfect equilibrium, it follows that $R_{1}^{\prime \prime}=R_{1}^{\prime \prime \prime}=0$. Since $\phi v_{0}\left(R_{0}^{*}, R_{1}^{*}\right)=1$ and $\left(R_{0}^{*}, R_{1}^{*}\right) \neq(0,0)$ by assumption, $\frac{\partial v_{i}}{\partial R_{i}}<0$ implies $\phi v_{0}(0,0)>1$, a contradiction. Hence, $\phi v_{1}\left(R_{1}^{\prime \prime}, 0\right)>1=\phi v_{1}\left(R_{1}^{\prime}, 0\right)$. Since $v_{i}$ is decreasing in $R_{i}$, it follows that $R_{1}^{\prime \prime}>R_{1}^{\prime}$ as claimed.

The fact that $R_{1}^{\prime \prime}>R_{1}^{\prime}$ can be used to establish that $R_{0}^{\prime \prime}>R_{0}^{\prime}$ as well. First, though, I argue that at the equilibrium $\left(R_{0}^{*}, R_{1}^{*}\right)$,

$$
\left.\frac{d R_{1}}{d R_{0}}\right|_{\phi v_{1}=1}>\left.\frac{d R_{1}}{d R_{0}}\right|_{\phi v_{0}=1}
$$

To see this, consider a neighborhood around $\left(R_{0}^{*}, R_{1}^{*}\right)$. Recall that for any admissible $\left(R_{0}, R_{1}\right)$ where $R_{0}$ is defined as $\xi R_{1}+(1-\xi) L$ for some $\xi \geq 0$, the proof of Proposition 2 above implies that $v_{1}\left(R_{1}, R_{0}\right)>$ $v_{0}\left(R_{0}, R_{1}\right)$ if and only if $1-\xi>h(\xi)$, which from Lemma 1 holds if and only if $\xi<\xi^{*}$. Since for any $\varepsilon>0, R_{0}^{*}+\varepsilon=\xi R_{1}^{*}+(1-\xi) L$ for some $\xi<\xi^{*}$, it follows that

$$
v_{1}\left(R_{1}^{*}, R_{0}^{*}+\varepsilon\right)>v_{0}\left(R_{0}^{*}+\varepsilon, R_{1}^{*}\right)
$$


Subtracting $v_{0}\left(R_{0}^{*}, R_{1}^{*}\right)=v_{1}\left(R_{1}^{*}, R_{0}^{*}\right)=\frac{1}{\phi}$ from both sides, dividing by $\varepsilon$, and taking the limit as $\varepsilon \rightarrow 0$ implies

$$
\frac{\partial v_{1}\left(R_{0}^{*}, R_{1}^{*}\right)}{\partial R_{0}} \geq \frac{\partial v_{0}\left(R_{1}^{*}, R_{0}^{*}\right)}{\partial R_{0}}
$$

We can further establish this inequality is strict. This is because if $\frac{\partial v_{0}\left(R_{1}^{*}, R_{0}^{*}\right)}{\partial R_{0}}=\frac{\partial v_{1}\left(R_{0}^{*}, R_{1}^{*}\right)}{\partial R_{0}}$, the derivative of $1-\xi-h(\xi)$ with respect to $\xi$ would be equal to 0 at $\xi=\xi^{*}$, which is contradicted by the proof of Lemma 1 above. Similarly, for any $\varepsilon>0$, Lemma 1 implies

$$
v_{0}\left(R_{0}^{*}, R_{1}^{*}+\varepsilon\right)>v_{1}\left(R_{1}^{*}+\varepsilon, R_{0}^{*}\right)
$$

and by an analogous argument,

$$
\frac{\partial v_{0}\left(R_{0}^{*}, R_{1}^{*}\right)}{\partial R_{1}} \geq \frac{\partial v_{1}\left(R_{1}^{*}, R_{0}^{*}\right)}{\partial R_{1}}
$$

Taking into account the fact that $\partial v_{i} / \partial R_{i}$ and $\partial v_{i} / \partial R_{-i}$ are both negative, it follows that

$$
\frac{\partial v_{0} / \partial R_{0}}{\partial v_{0} / \partial R_{1}}>\frac{\partial v_{1} / \partial R_{0}}{\partial v_{1} / \partial R_{1}}
$$

which implies

$$
\left.\frac{d R_{1}}{d R_{0}}\right|_{\phi v_{1}=1}=-\frac{\partial v_{1} / \partial R_{0}}{\partial v_{1} / \partial R_{1}}>-\frac{\partial v_{0} / \partial R_{0}}{\partial v_{0} / \partial R_{1}}=\left.\frac{d R_{1}}{d R_{0}}\right|_{\phi v_{0}=1}
$$

Since there can be only one point at which $\phi v_{i}\left(R_{i}, R_{-i}\right)=1$, the two contours sets ${ }_{i}$ intersect only at $\left(R_{0}^{*}, R_{1}^{*}\right)$, and by continuity it follows that $R_{0}^{\prime \prime}>R_{0}^{\prime}$.

With these observations, I can finally establish that there exists no other equilibrium $\left(\widehat{R}_{i}, \widehat{R}_{-i}\right)$ in which $\widehat{R}_{i}=0$ for some $i \in\{0,1\}$ and $\phi v_{i}\left(0, \widehat{R}_{-i}\right)<1$. This is because if such an equilibrium existed, by definition it must be true that $\phi v_{i}\left(0, \widehat{R}_{-i}\right) \leq 1$. Since $\phi v_{i}\left(0, R_{-i}^{\prime \prime}\right)=1$ by definition, monotonicity implies $\widehat{R}_{-i} \geq R_{-i}^{\prime \prime}>R_{-i}^{\prime}$. But since $R_{-i}>R_{-i}^{\prime}$, it follows that $\phi v_{-i}\left(R_{-i}, 0\right)<1$. For this to be an equilibrium, $\widehat{R}_{-i}=0$. But since there exists an $\left(R_{0}^{*}, R_{1}^{*}\right) \neq(0,0)$ such that $\phi v_{i}\left(R_{i}^{*}, R_{-i}^{*}\right)=1$, it follows that $\phi v_{i}(0,0)>1$, a contradiction.

Finally, suppose there exists no pair $\left(R_{0}^{*}, R_{1}^{*}\right)$ such that $\phi v_{0}\left(R_{0}^{*}, R_{1}^{*}\right)=\phi v_{1}\left(R_{0}^{*}, R_{1}^{*}\right)=1$. We need to establish that there still exists a unique Markov-perfect equilibrium. Suppose first that $\phi v_{0}(0,0) \leq 1$. Then for any $\left(R_{0}, R_{1}\right) \geq(0,0)$ where $\left(R_{0}, R_{1}\right) \neq(0,0)$, it must be the case that $\phi v_{0}\left(R_{0}, R_{1}\right)<1$. This implies $R_{0}=0$ in any equilibrium, and since $R_{0} \geq R_{1}$ in any equilibrium according to Proposition 2, $R_{0}=R_{1}=0$ must be the unique equilibrium. If we rewrite $R_{0}$ as $\xi R_{1}+(1-\xi) L$, then $\xi=1>\xi^{*}$. But recall from Lemma 1 that this implies $v_{1}(0,0)<v_{0}(0,0)$. Since $\phi v_{0}(0,0) \leq 1$, it follows that $(0,0)$ is in fact an equilibrium.

This leaves the case where (i) there exists no pair $\left(R_{0}^{*}, R_{1}^{*}\right)$ such that $\phi v_{0}\left(R_{0}^{*}, R_{1}^{*}\right)=\phi v_{1}\left(R_{0}^{*}, R_{1}^{*}\right)=1$ and (ii) $\phi v_{0}(0,0)>1$. By continuity, there exists an $R_{0}^{\prime}<L$ such that $\phi v_{0}\left(R_{0}^{\prime}, 0\right)=1$. Then I claim $\left(R_{0}, R_{1}\right)=\left(R_{0}^{\prime}, 0\right)$ is the unique Markov perfect equilibrium. Consider again two cases. First, suppose 
that $\phi v_{1}(0,0) \leq 1$. In that case, monotonicity implies $\phi v_{1}\left(0, R_{0}^{\prime}\right)<1$ given that $R_{0}^{\prime}>0$, so that $\phi v_{1}\left(0, R_{0}^{\prime}\right) \leq 1$ and $\left(R_{0}^{\prime}, 0\right)$ is indeed an equilibrium. Moreover, since $\phi v_{1}(0,0) \leq 1$, then $R_{1}=0$ in any equilibrium, and it follows that $\left(R_{0}^{\prime}, 0\right)$ is the unique equilibrium. Lastly, suppose $\phi v_{1}(0,0)>1$. Once again, define $R_{0}^{\prime \prime}$ such that $\phi v_{0}\left(0, R_{0}^{\prime \prime}\right)=1$, with the convention of setting $R_{0}^{\prime \prime}=\infty$ if no such value exists. We need to show that $R_{0}^{\prime}>R_{0}^{\prime \prime}$, which insures $\phi v_{1}\left(0, R_{0}^{\prime}\right) \leq 1$. Suppose not, i.e. suppose $R_{0}^{\prime \prime} \geq R_{0}^{\prime}$. But using the same argument as before, we know that $R_{1}^{\prime \prime}>R_{1}^{\prime}$. If $R_{0}^{\prime \prime} \geq R_{0}^{\prime}$, then by continuity 0 and 1 must intersect, which contradicts the supposition that there exists no solution $\left(R_{0}^{*}, R_{1}^{*}\right)$. Hence, $\phi v_{1}\left(0, R_{0}^{\prime}\right) \leq 1$, so that $\left(R_{0}^{\prime}, 0\right)$ is an equilibrium, and since $R_{1}=0$ in any equilibrium, which insures the equilibrium above is unique.

Proof of Lemma 2 (in text): Consider the equation $v_{0}\left(R^{*}, R^{*}\right)=v_{1}\left(R^{*}, R^{*}\right)$. It implies

$$
\frac{\mu}{\kappa}\left[\frac{Z_{0}}{Z_{1}}-\frac{Z_{1}}{Z_{0}}\right]\left(L-R^{*}\right)^{1-\alpha}=\frac{\lambda\left(\omega\left(R^{*}\right)+\mu\right)}{(\lambda-1)(1-\alpha)}\left[\frac{1}{Z_{1}}-\frac{1}{Z_{0}}\right]
$$

Define $y_{i}=L-R_{i}$. Using the assumption that $R_{i}<L$ implies $y_{i} \neq 0$, we can rearrange the condition $v_{0}(R, R)=v_{1}(R, R)$ by dividing both sides by $y^{\alpha}$ and expanding out $\omega(L-y)$ to obtain

$$
\mu\left(Z_{1}+Z_{0}\right) \frac{y^{1-\alpha}}{\kappa}+\frac{\lambda}{(\lambda-1)(1-\alpha)}(1-(1-\alpha) \ln \lambda) \phi y=\frac{\lambda(\omega(L)+\mu)}{(\lambda-1)(1-\alpha)}
$$

The LHS of this equation is monotonically increasing in $y$, and ranges from 0 to $\infty$ as $y$ ranges from 0 to $\infty$. Since the RHS above is strictly positive, there exists a unique value $y^{*}$ for which the equation is satisfied. This translates into a unique solution $R^{*}=L-y^{*}$.

Equation (5.4) further implies that $y^{*}$ is monotonically increasing in $\kappa$. Taking limits, $y^{*} \rightarrow 0$ as $\kappa \rightarrow 0$ and $y^{*} \rightarrow L+\frac{\rho+2 \mu}{(1-(1-\alpha) \ln \lambda) \phi}$ as $\kappa \rightarrow \infty$. If we evaluate $v_{i}\left(R^{*}, R^{*}\right)$ and substitute in from (5.4), we obtain

$$
\begin{aligned}
v_{i} & =(\lambda-1) \frac{\left(\omega(L-y)+\mu \frac{Z_{-i}}{Z_{i}}\right) y^{*}-\frac{(\omega(L-y)+\mu) \lambda \kappa\left(y^{*}\right)^{\alpha}}{(\lambda-1)(1-\alpha) Z_{i}}}{\omega^{2}\left(L-y_{\kappa}^{*}\right)-\mu^{2}} \\
& =(\lambda-1) \frac{\left(\omega\left(L-y^{*}\right)+\mu \frac{Z_{-i}}{Z_{i}}\right) y^{*}-\frac{\mu\left(Z_{1}+Z_{0}\right) y^{*}}{Z_{i}}}{\omega^{2}\left(L-y^{*}\right)-\mu^{2}} \\
& =\frac{(\lambda-1) y^{*}}{\omega\left(L-y^{*}\right)+\mu}
\end{aligned}
$$

Hence, $v_{i}\left(R^{*}, R^{*}\right)$ is monotonically increasing in $y^{*}$, which in turn is monotonically increasing in $\kappa$. Since $y^{*} \in\left[0, L+\frac{\rho+2 \mu}{(1-(1-\alpha) \ln \lambda) \phi}\right), v_{i}$ ranges between 0 and $\infty$. The existence of $\kappa^{*}$ follows from continuity.

Proof of Proposition 4: Consider a fixed value $\kappa>\kappa^{*}$, where $\kappa^{*}$ is defined in Lemma 2. As in the proof of Lemma 2, it will be useful to work with $y_{i}=L-R_{i}$. Consider the set

$$
S=\left\{\left(y_{0}, y_{1}\right) \mid v_{0}\left(L-y_{0}, L-y_{1}\right)=v_{1}\left(L-y_{1}, L-y_{0}\right)\right\}
$$


The proposition follows if I can show that within this set there exists an element $\left(y_{0}, y_{1}\right) \in S$ such that $y_{0}>y_{1}$ and $\phi v_{i}\left(L-y_{i}, L-y_{-i}\right)=1$ for $i \in\{0,1\}$.

Consider first the case where $y_{1}=0$. For this value, we have

$$
\begin{aligned}
& v_{0}=\frac{(\lambda-1) \omega(L) y_{0}-\frac{\omega(L)+\mu \lambda \kappa}{(1-\alpha) Z_{0}} y_{0}^{\alpha}}{\omega\left(L-y_{0}\right) \omega(L)-\mu^{2}} \\
& v_{1}=0
\end{aligned}
$$

Hence, there are exactly two values of $y_{0}$ for which $v_{0}\left(L-y_{0}, L\right)=v_{1}\left(L, L-y_{0}\right)$, namely $y_{0}=0$ and

$$
y_{0}=\widetilde{y}_{0} \equiv\left[\frac{(\omega(L)+\mu) \lambda \kappa}{\omega(L)(\lambda-1)(1-\alpha) Z_{0}}\right]^{\frac{1}{1-\alpha}}
$$

By the implicit function theorem, there exist continuous functions $y_{0}(\cdot)$ defined in a neighborhood of $y_{1}=0$ such that $y_{0}\left(y_{1}\right) \rightarrow 0$ and $y_{0}\left(y_{1}\right) \rightarrow \widetilde{y}_{0}$ as $y_{1} \rightarrow 0$ which satisfy $v_{0}\left(L-y_{0}\left(y_{1}\right), L-y_{1}\right)=$ $v_{0}\left(L-y_{1}, L-y_{0}\left(y_{1}\right)\right)$.

For $y_{1} \neq 0$, we can rewrite the equation $v_{0}=v_{1}$ in terms of $y_{1}$ and $\xi=\frac{y_{0}}{y_{1}}$. The condition that $v_{1}=v_{0}$ can be rewritten as

$$
\frac{\lambda \kappa y_{1}^{\alpha-1}}{Z_{1}(\lambda-1)(1-\alpha)}\left(A_{0}-A_{1} \xi-A_{2} \xi^{\alpha}\right)-1+\xi+h(\xi)=0
$$

where

$$
\begin{aligned}
& A_{0}=\frac{\omega(L)+\mu}{\omega(L)} \\
& A_{1}=\frac{(1-(1-\alpha) \ln \lambda) \phi y_{1}}{\omega(L)} \\
& A_{2}=\frac{\omega\left(L-y_{1}\right)+\mu}{\omega(L)} \frac{Z_{1}}{Z_{0}}
\end{aligned}
$$

and as in Lemma 1,

$$
h(\xi)=\frac{\mu}{\omega(L)}\left[\frac{Z_{1}}{Z_{0}} \xi^{\alpha}-\frac{Z_{0}}{Z_{1}} \xi^{1-\alpha}\right]
$$

For notational convenience, I will rewrite (5.5) more compactly as

$$
Q\left(\xi ; y_{1}\right)=0
$$

The implicit functions $y_{0}\left(y_{1}\right)$ described above which limit to 0 and $\widetilde{y}_{0}$ establish the existence of functions $\xi\left(y_{1}\right)$ defined locally near $y_{1}=0$ that limit to $\xi=\left(\frac{Z_{0}}{Z_{1}}\right)^{\frac{1}{\alpha}}$ and $\xi=\infty$, respectively, as $y_{1} \rightarrow 0$.

Define $y^{*}$ as in Lemma 2. Differentiate $Q\left(\xi ; y_{1}\right)$ with respect to $\xi$ twice to obtain

$$
\frac{\partial^{2} Q}{\partial \xi^{2}}=h^{\prime \prime}(\xi)+\alpha(1-\alpha) \frac{\lambda \kappa \xi^{\alpha-2}}{Z_{1}(\lambda-1)(1-\alpha)} A_{2} y_{1}^{\alpha-1}
$$


Substituting in for $h^{\prime \prime}(\xi)$, we obtain

$$
\frac{\partial^{2} Q}{\partial \xi^{2}}=\alpha(1-\alpha)\left(\frac{\mu}{\omega(L)}\left[\frac{Z_{0}}{Z_{1}} \xi^{-\alpha-1}-\frac{Z_{1}}{Z_{0}} \xi^{\alpha-2}\right]+\frac{\lambda \kappa \xi^{\alpha-2}}{Z_{1}(\lambda-1)(1-\alpha)} A_{2} y_{1}^{\alpha-1}\right)
$$

Now, note that

$$
\begin{aligned}
A_{2} y_{1}^{\alpha-1} & =\frac{\omega\left(L-y_{1}\right)+\mu}{\omega(L)} \frac{Z_{1}}{Z_{0}} y_{1}^{\alpha-1} \\
& =\left[\frac{\omega(L)+\mu}{\omega(L)} y_{1}^{\alpha-1}-\frac{(1-(1-\alpha) \ln \lambda) \phi y_{1}^{\alpha}}{\omega(L)}\right] \frac{Z_{1}}{Z_{0}}
\end{aligned}
$$

is decreasing in $y_{1}$. Hence, if we can show that $\frac{\partial^{2} Q}{\partial \xi^{2}}>0$ for some $y_{1}^{\prime}$, it follows that $\frac{\partial^{2} Q}{\partial \xi^{2}}>0$ for all $y_{1} \leq y_{1}^{\prime}$. For $y_{1}=y^{*}$, we know from the proof of Lemma 2 that $y^{*}$ satisfies

$$
\frac{\lambda \kappa\left(y^{*}\right)^{\alpha-1}}{Z_{1}(\lambda-1)(1-\alpha)}=\frac{\mu}{\omega\left(L-y^{*}\right)+\mu}\left(\frac{Z_{1}+Z_{0}}{Z_{1}}\right)
$$

Substituting this into the expression for $\frac{\partial^{2} Q}{\partial \xi^{2}}$ yields

$$
\frac{\partial^{2} Q}{\partial \xi^{2}}=\alpha(1-\alpha)\left(\frac{\mu}{\omega(L)} \frac{Z_{0}}{Z_{1}} \xi^{-\alpha-1}+\frac{\mu}{\omega(L)} \xi^{\alpha-2}\right)>0
$$

Hence, for all $y_{1} \leq y^{*}, Q\left(\xi ; y_{1}\right)$ is convex in $\xi$. This will prove important in what follows.

Before I proceed, I introduce the notation $\left(y_{0}, y_{1}\right) \rightsquigarrow\left(y_{0}^{\prime}, y_{1}^{\prime}\right)$ to denote the case in which there exists a continuous mapping $y_{1}(\tau)>0$ and a continuous mapping $y_{0}(\tau)$ defined for $\tau \in(0,1)$ such that

1. $\lim _{\tau \rightarrow 0} y_{1}(\tau)=y_{1}$ and $\lim _{\tau \rightarrow 0} y_{0}(\tau)=y_{0}$

2. $\lim _{\tau \rightarrow 1} y_{1}(\tau)=y_{1}^{\prime}$ and $\lim _{\tau \rightarrow 1} y_{0}(\tau)=y_{0}^{\prime}$

3. For all $\tau \in(0,1),\left(y_{0}(\tau), y_{1}(\tau)\right) \in S$, i.e. $Q\left(\xi(\tau) ; y_{1}(\tau)\right)=0$ for $\xi(\tau)=\frac{y_{0}(\tau)}{y_{1}(\tau)}$

The notation $\lim _{\tau \rightarrow 1} y(\tau)=\infty$ denotes, as usual, that for every $N>0$, there exists a $\tau_{N}$ such that $y(\tau)>$ $N$ for all $\tau>\tau_{N}$. Thus, we can describe a path in which $y_{i}^{\prime}=\infty$ for some $i$. Note that if we can establish that $\left(y^{*}, y^{*}\right) \rightsquigarrow\left(\widetilde{y}_{0}, 0\right)$, the statement of the proposition follows from a simple continuity argument: since $\phi v_{0}\left(L-y^{*}, L-y^{*}\right)>1$ for $\kappa>\kappa^{*}$ but $\phi v_{0}\left(\widetilde{y}_{0}, 0\right)=0$, there exists some $\tau$ for which $\left(y_{0}(\tau), y_{1}(\tau)\right) \in S$ and where $\phi v_{i}\left(L-y_{i}(\tau), L-y_{-i}(\tau)\right)=1$. Since $v_{0}(L-y, L-y)=v_{1}(L-y, L-y)$ if and only if $y=y^{*}$, and since $\widetilde{y}_{0}>0$, it follows that $y_{0}(\tau)>y_{1}(\tau)$ by continuity.

I now break down my analysis into different cases, depending on the sign of $\frac{\partial Q}{\partial \xi}$ evaluated at $\xi=1$ and $y_{1}=y^{*}$. For convenience, a graphical view of the set $S$ corresponding to each of the three cases (for particular parameter values) is provided in Figure A3. 
Case I: $\frac{\partial Q\left(1 ; y^{*}\right)}{\partial \xi}>0$

I claim this is enough to establish that $\left(y^{*}, y^{*}\right) \rightsquigarrow\left(\widetilde{y}_{0}, 0\right)$, which from above is enough to establish the proposition. I first argue that there exists a $y_{1}^{\prime} \in\left[0, y^{*}\right)$ such that $\left(y^{*}, y^{*}\right) \rightsquigarrow\left(y_{0}^{\prime}, y_{1}^{\prime}\right)$ where $\frac{y_{0}^{\prime}}{y_{1}^{\prime}}=\infty$. For suppose not. Since $\frac{\partial Q\left(1 ; y_{1}\right)}{\partial y_{1}}>0$ for all $y_{1}$, it follows that $Q\left(1 ; y_{1}\right)<0$ for all $y_{1}<y^{*}$. Furthermore, since $Q\left(\xi ; y^{*}\right)$ is convex in $\xi$, it also follows that $Q\left(\xi ; y^{*}\right)>0$ for all $\xi>1$. By continuity, then, the assumption that $\left(y^{*}, y^{*}\right) \not \rightarrow\left(\infty, y_{1}\right)$ for all $y_{1} \in\left(0, y^{*}\right)$ implies that for each $y_{1} \in\left(0, y^{*}\right)$ there must exist some $\xi\left(y_{1}\right)>1$ such that $Q\left(\xi\left(y_{1}\right) ; y_{1}\right)>0$. Applying the intermediate value theorem, we can deduce that for every $y_{1} \in\left(0, y^{*}\right)$ there exists a $\xi^{*}\left(y_{1}\right)>1$ such that $Q\left(\xi^{*}\left(y_{1}\right) ; y_{1}\right)=0$. Since $Q$ is continuous and convex in $\xi$ for all $y_{1} \leq y^{*}$, the root $\xi^{*}\left(y_{1}\right)$ is the unique value of $\xi>1$ such that $Q\left(\xi^{*}\left(y_{1}\right) ; y_{1}\right)=1$, is continuous in $y_{1}$, and $\lim _{y_{1} \uparrow y_{\kappa}^{*}} \xi^{*}\left(y_{1}\right)=1$. Hence, $\left(y^{*}, y^{*}\right) \rightsquigarrow\left(\xi^{*}\left(y_{1}\right), y_{1}\right)$. Taking the limit as $y_{1} \downarrow 0$, it follows that $\left(y^{*}, y^{*}\right) \rightsquigarrow\left(\widetilde{y}_{0}, 0\right)$, since the unique root greater than one for which $\lim _{y_{1} \rightarrow 0} Q\left(\xi ; y_{1}\right)=0$ limits to $\infty$. But then $\left(y^{*}, y^{*}\right) \rightsquigarrow\left(y_{0}^{\prime}, y_{1}^{\prime}\right)$ such that $\frac{y_{0}^{\prime}}{y_{1}^{\prime}}=\infty$, which is a contradiction. Since $\lim _{\xi \rightarrow \infty} \frac{\partial Q}{\partial y_{1}}<0$ for all $y_{1}>0$, there can exist at most one $y_{1}$ for which $\lim _{\xi \rightarrow \infty} Q\left(\xi ; y_{1}\right)=0$. Since $\lim _{\xi \rightarrow \infty} Q(\xi ; 0)=0$, it follows that $\left(y^{*}, y^{*}\right) \rightsquigarrow\left(\widetilde{y}_{0}, 0\right)$.

Case II: $\frac{\partial Q\left(1 ; y^{*}\right)}{\partial \xi}=0$.

Since $Q\left(1 ; y^{*}\right)$ is strictly convex, it follows that $Q\left(\xi ; y^{*}\right)>0$ for all $\xi \neq 1$. The fact that $\left(y^{*}, y^{*}\right) \rightsquigarrow$ $\left(\widetilde{y}_{0}, 0\right)$ then follows from the same argument as in Case I.

Case III: $\frac{\partial Q\left(1 ; y^{*}\right)}{\partial \xi}<0$

In this case, the arguments above can no longer be used to establish that $\left(y^{*}, y^{*}\right) \rightsquigarrow\left(\widetilde{y}_{0}, 0\right)$. However, I argue that if $\left(y^{*}, y^{*}\right) \not \leftrightarrow\left(\widetilde{y}_{0}, 0\right)$, then there exists some $y_{1}>0$ such that $\left(y^{*}, y^{*}\right) \rightsquigarrow\left(\infty, y_{1}\right)$ where $\lim _{\tau \rightarrow 1} \frac{y_{0}(\tau)}{y_{1}(\tau)}>1$ along any such connecting path. As I argue below, this condition is also sufficient to establish the proposition.

Again, the proof is by contradiction. Suppose the claim is false, i.e. suppose $\left(y^{*}, y^{*}\right) \not \leftrightarrow\left(\widetilde{y}_{0}, 0\right)$ and $\left(y^{*}, y^{*}\right) \not \leftrightarrow\left(\infty, y_{1}\right)$ for all $y_{1}>0$, including $y_{1}=\infty$. If we differentiate $\xi$ with respect to $y_{1}$ along the curve $Q\left(\xi ; y_{1}\right)=0$, we obtain

$$
\left.\frac{d \xi}{d y_{1}}\right|_{\left(\xi ; y_{1}\right)=\left(1 ; y^{*}\right)}=-\frac{\partial Q / \partial y_{1}}{\partial Q / \partial \xi}>0
$$

where the last inequality follows from the fact that $\frac{\partial Q\left(1 ; y_{1}\right)}{\partial y_{1}}>0$ for all $y_{1}$. Hence, if $\left(y^{*}, y^{*}\right) \rightsquigarrow\left(y_{0}, y_{1}\right)$ for some $y_{0}>y^{*}$, it follows from continuity and the uniqueness of $y^{*}$ that $y_{0}>y_{1}$. Next, since $\left(y^{*}, y^{*}\right) \ngtr\left(\infty, y_{1}\right)$ for all $y_{1}$ (including $\left.y_{1}=\infty\right)$ by assumption, it follows that

$$
\bar{y}=\sup \left\{y_{0} \mid\left(y^{*}, y^{*}\right) \rightsquigarrow\left(y_{0}, y_{1}\right) \text { for some } y_{1}\right\}
$$

is finite. It follows that for any $y_{0}>y^{*}$, it must be the case that $\left(y^{*}, y^{*}\right) \not \rightarrow\left(y_{0}, y_{1}\right)$ if $y_{1} \geq \bar{y}$. Thus, any continuous path that originates at $\left(y^{*}, y^{*}\right)$ for which $y_{0}(\tau)>y^{*}$ is bounded in its $y_{1}$ term from above by $\bar{y}$. But the fact that $\lim _{y_{1} \rightarrow 0} Q\left(\xi ; y_{1}\right)<0$ for all finite $\xi>0$, together with continuity and the 
uniqueness of $y^{*}$, implies that this occurs only if $\left(y^{*}, y^{*}\right) \rightsquigarrow\left(y_{0}, y_{1}\right)$ for some $y_{0}>y^{*}$ and some $y_{1}$ such that $\lim _{\tau \rightarrow 1} \frac{y_{0}(\tau)}{y_{1}(\tau)}=\infty$. Since $y_{0}(\tau) \leq \bar{y}$ for all $\tau$, this requires that $\lim _{\tau \rightarrow 1} y_{1}(\tau)=0$. But this contradicts the fact that $\left(y^{*}, y^{*}\right) \not \rightarrow\left(\widetilde{y}_{0}, 0\right)$. It follows that either $\left(y^{*}, y^{*}\right) \rightsquigarrow\left(\widetilde{y}_{0}, 0\right)$ or $\left(y^{*}, y^{*}\right) \rightsquigarrow\left(\infty, y_{1}\right)$ where $\lim _{\tau \rightarrow 1} \frac{y_{0}(\tau)}{y_{1}(\tau)}>1$ along this path.

The final step is to prove that the fact that $\left(y^{*}, y^{*}\right) \rightsquigarrow\left(\infty, y_{1}\right)$ where $\lim _{\tau \rightarrow 1} \frac{y_{0}(\tau)}{y_{1}(\tau)}>1$ implies there exists a solution $\left(y_{0}, y_{1}\right)$ with $y_{0}>y_{1}$ such that $\phi v_{0}\left(L-y_{0}, L-y_{1}\right)=\phi v_{1}\left(L-y_{1}, L-y_{0}\right)=1$. Consider

$$
\lim _{y_{i} \rightarrow \infty} v_{i}\left(L-y_{i}, L-y_{-i}\right)=\lim _{y_{i} \rightarrow \infty} \frac{(\lambda-1)\left[\omega\left(L-y_{-i}\right) y_{i}+\left(\mu \frac{Z_{-i}}{Z_{i}} y_{-i}^{1-\alpha}-\frac{\left(\omega\left(L-y_{-i}\right)+\mu\right) \lambda \kappa}{(1-\alpha)(\lambda-1) Z_{i}}\right) y_{i}^{\alpha}\right]}{\omega\left(L-y_{i}\right) \omega\left(L-y_{-i}\right)-\mu^{2}}
$$

As $y_{i} \rightarrow \infty$, the numerator converges to $\pm \infty$, depending on the sign of $\omega\left(L-y_{-i}\right)$, and since $\omega\left(L-y_{i}\right) \rightarrow$ $-\infty$, the denominator converges to $\pm \infty$, again depending on the sign of $\omega\left(L-y_{-i}\right)$. Applying L'Hopital's rule, we obtain

$$
\lim _{y_{i} \rightarrow \infty} v_{i}\left(L-y_{i}, L-y_{-i}\right)=-\frac{(\lambda-1) \omega\left(L-y_{-i}\right)}{\omega^{\prime}(\cdot) \omega\left(L-y_{-i}\right)}<0
$$

Hence, since $v_{0}\left(L-y_{0}, L-y_{1}\right)<0$ as $y_{0} \rightarrow \infty$, it follows by continuity that there exists a pair $\left(y_{0}, y_{1}\right)$ such that $\phi v_{i}\left(L-y_{i}, L-y_{-i}\right)=1$. Again, since $v_{0}(L-y, L-y)=v_{1}(L-y, L-y)$ if and only if $y=y^{*}$ and $\lim _{\tau \rightarrow 1} \frac{y_{0}(\tau)}{y_{1}(\tau)}>1$, it follows that $y_{0}(\tau)>y_{1}(\tau)$ by continuity.

Remark: all cases for $\frac{\partial Q\left(1 ; y^{*}\right)}{\partial \xi}$ are possible, depending on parameter values. In cases II and III, there will be multiple solutions to the problem $\phi v_{i}\left(R_{i}, R_{-i}\right)=1$, i.e. in addition to the solution identified above, there also exists a second solution with $R_{0}>R_{1}$. However, the existence of multiple solutions need not imply multiple equilibria, since these solutions may involve negative values of $R_{i}$.

Proof of Proposition 5: Given that firms maximize expected profits, a firm that has successfully innovated will choose the time to implement by solving

$$
\max _{s} E_{t}\left[e^{-\rho s} \frac{1 / P_{t+s}}{1 / P_{t}} v_{t+s}\right]
$$

Suppose the solution in Proposition 4 is an equilibrium. The Proposition follows if we can show that $s=0$. Clearly, if $Z_{t+s}=Z_{t}$, there is no benefit from delay, since $v_{t+s}=v_{t}$ and so in the best case scenario the firm becomes the leader and earns $v_{t}$ discounted at a positive rate. Thus, given other agents are implementing immediately and innovating in accordance with Proposition 4, a firm will only delay implementation until a change in the level of productivity. If the current level of productivity is equal to $Z_{1}$, then given $v_{0}=v_{1}=\frac{1}{\phi}$ in equilibrium, waiting until a regime change yields at most

$$
\frac{\mu}{\rho+\mu} \frac{P_{1}}{P_{0}} v=\frac{\mu}{\rho+\mu} \frac{Z_{0}}{Z_{1}}\left(\frac{L-R_{1}}{L-R_{0}}\right)^{\alpha} v
$$

assuming the firm is the leading producer when it implements. Since $R_{1}>R_{0}$, it follows that this is less than $v$. Thus, there is no reason to delay an innovation uncovered when productivity is high. Conversely, 
there will be no reason to delay an innovation that is discovered when productivity is low if

$$
\frac{\mu}{\rho+\mu} \frac{Z_{1}}{Z_{0}}\left(\frac{L-R_{0}}{L-R_{1}}\right)^{\alpha}<1
$$

By assumption, $\frac{\mu}{\rho+\mu} \frac{Z_{1}}{Z_{0}}<1$. Moreover, by continuity, the solution $\left(R_{0}, R_{1}\right)$ identified in Proposition 4 limits to $\left(R^{*}, R^{*}\right)$ as $\kappa \rightarrow \kappa^{*}$. Thus, there will be no benefit from delay even though $R_{1}>R_{0}$ for $\kappa$ close to $\kappa^{*}$. 
Figure 1

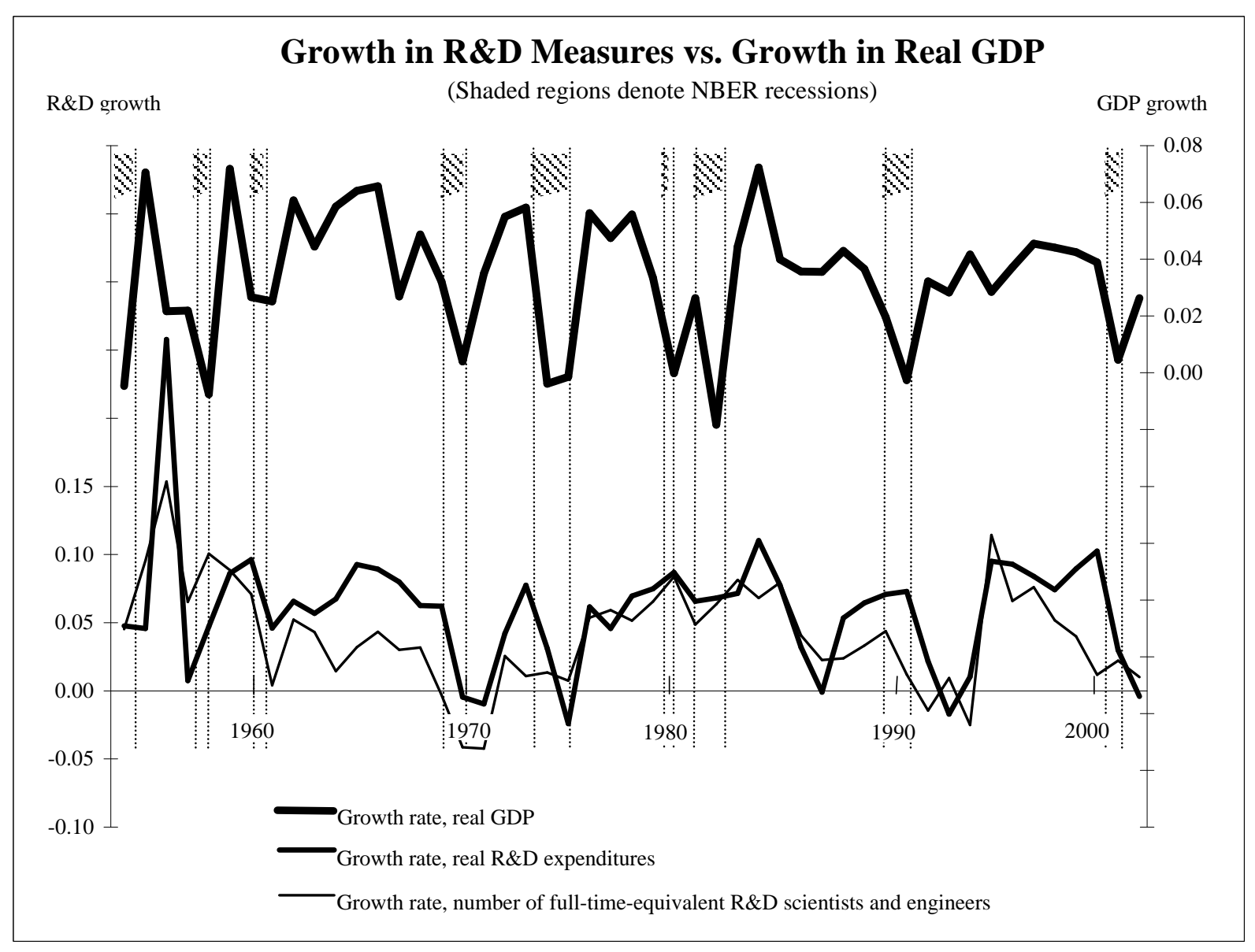

Source: National Science Foundation 
Figure 2

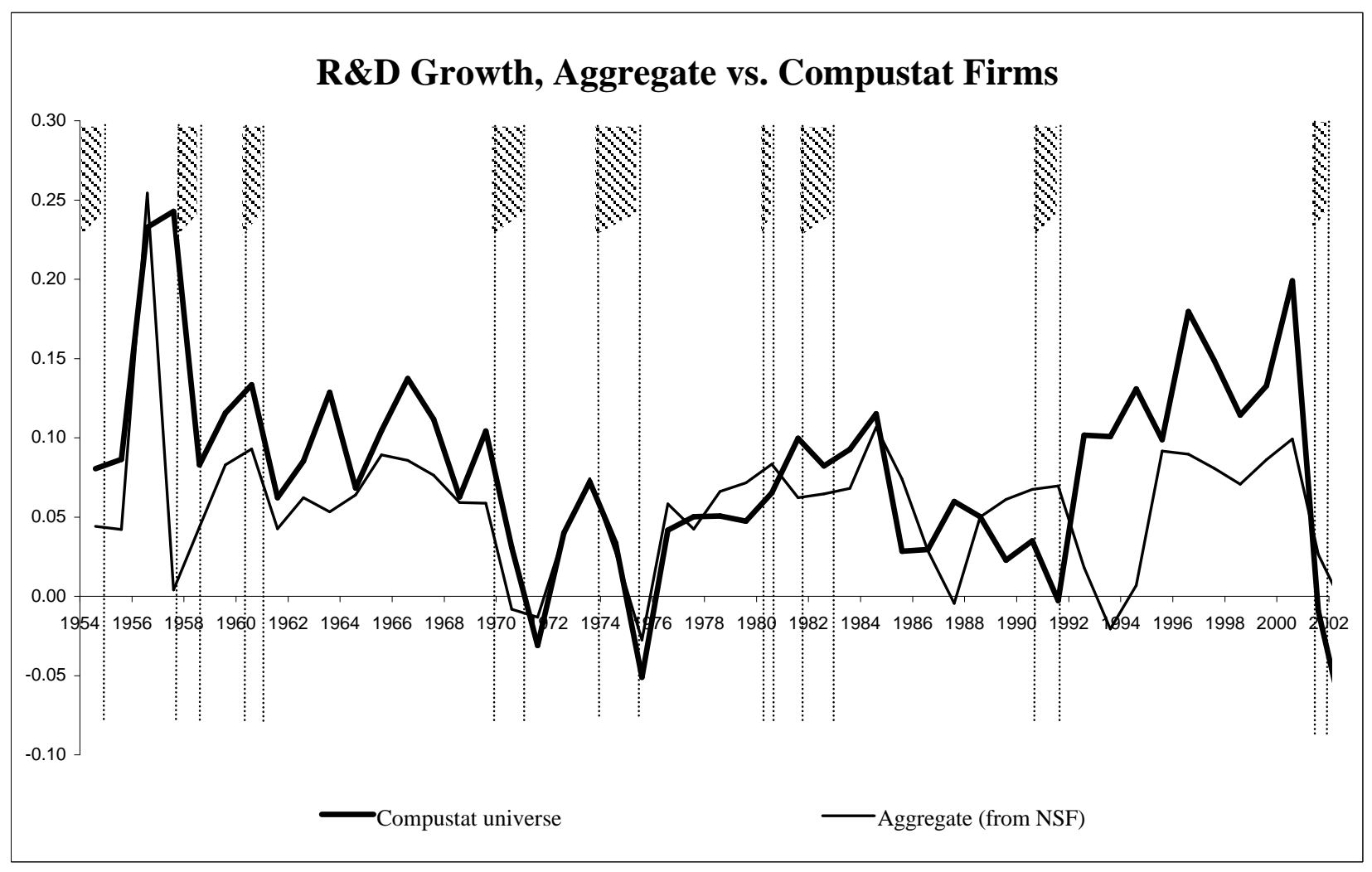

Source: National Science Foundation and S\&P's Compustat database

Figure 3

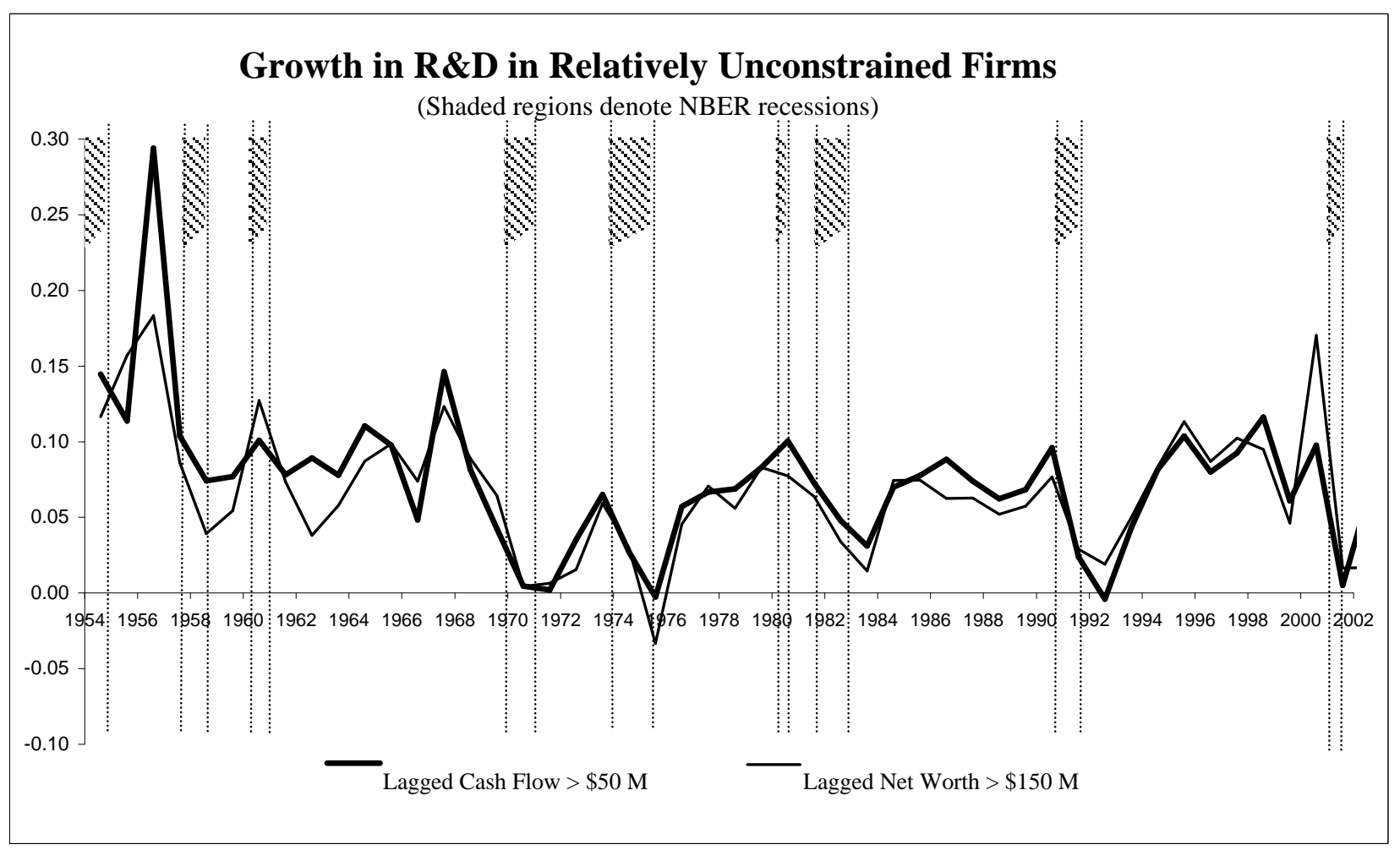

Source: S\&P Compustat database 


\section{Figure 4}

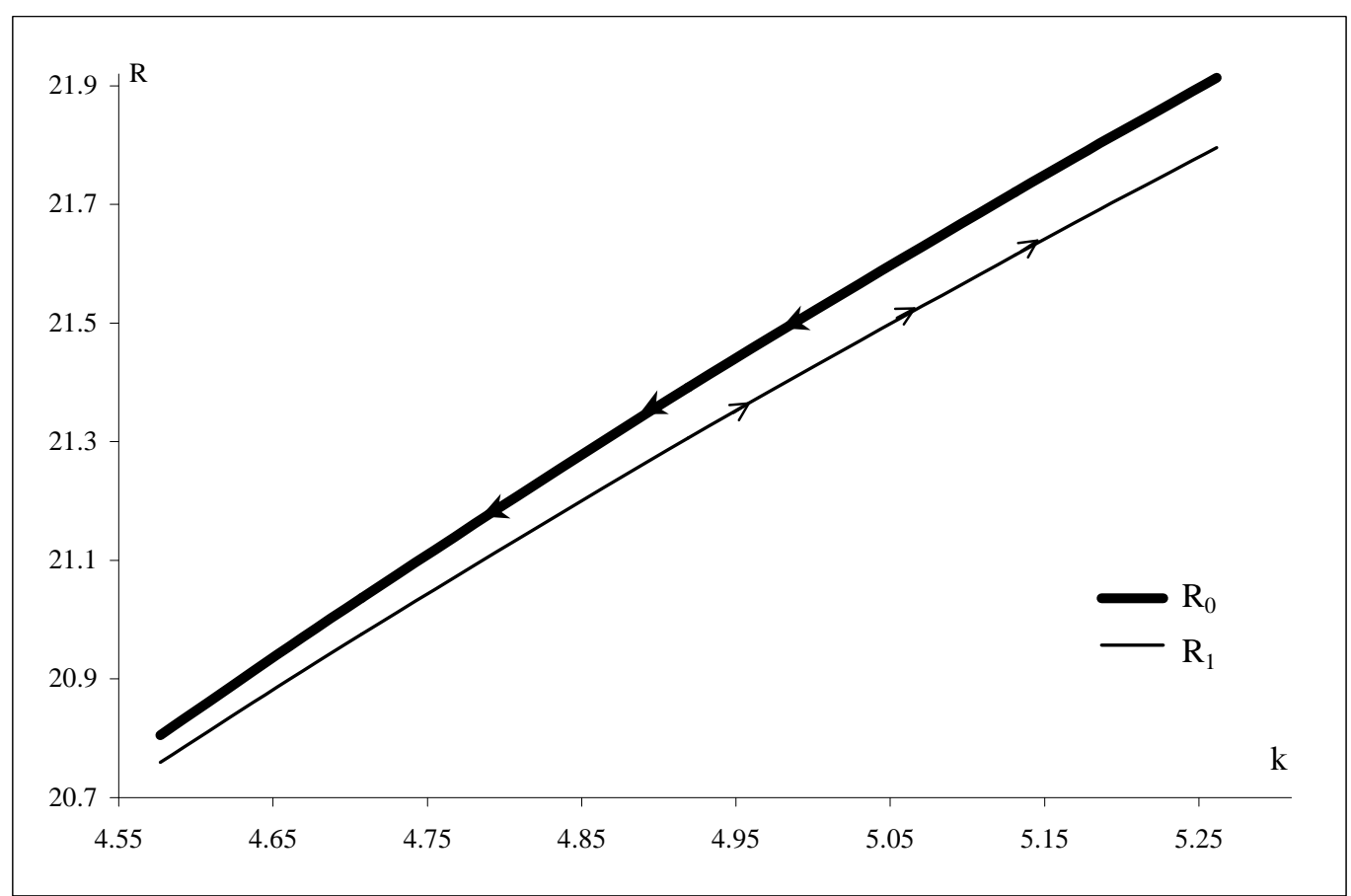

Optimal R\&D as a function of capital ratio $\mathrm{k}$

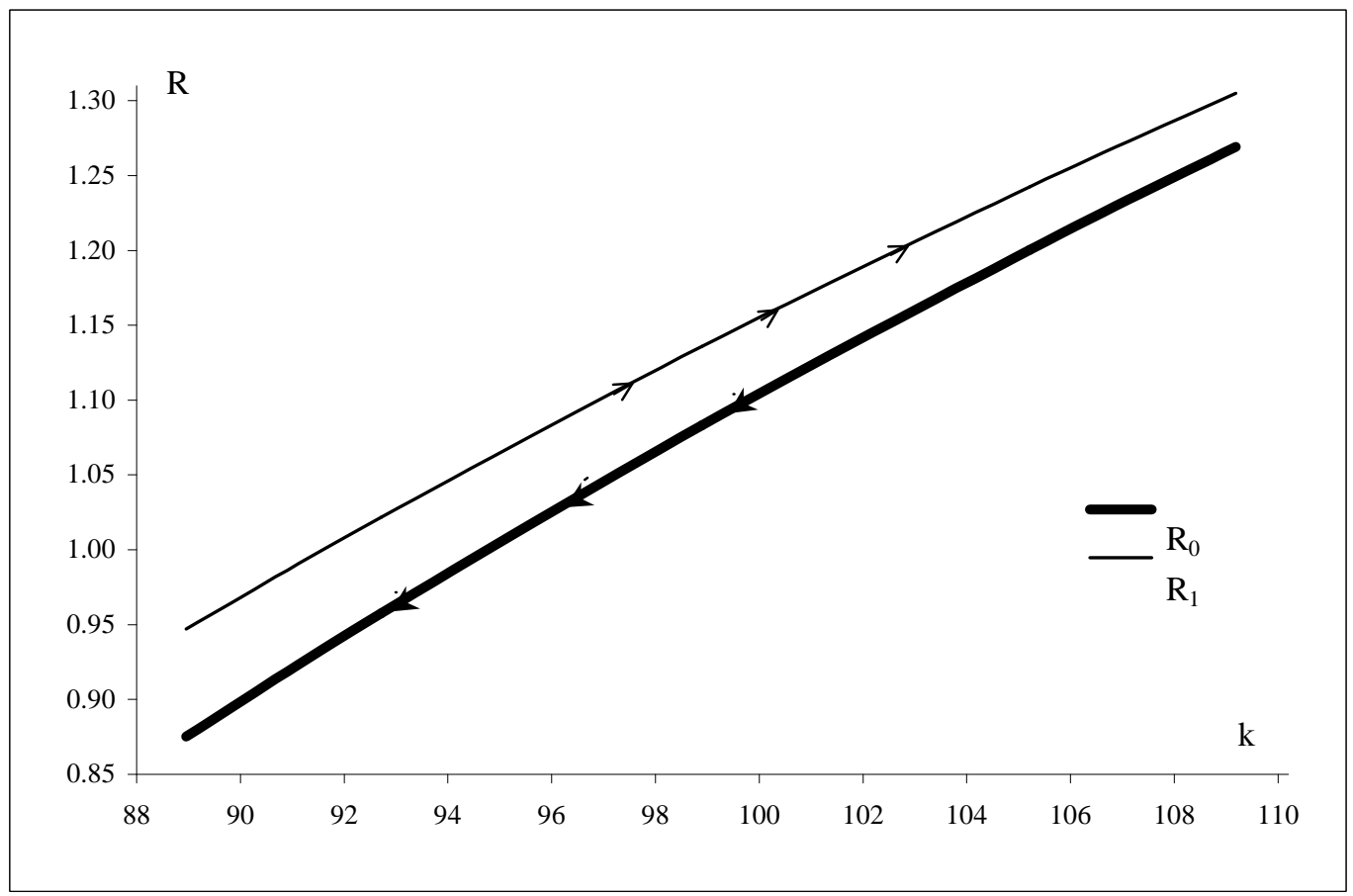

Equilibrium R\&D as a function of capital ratio $\mathrm{k}$

Note: arrows indicate direction of capital accumulation for each respective level of productivity 


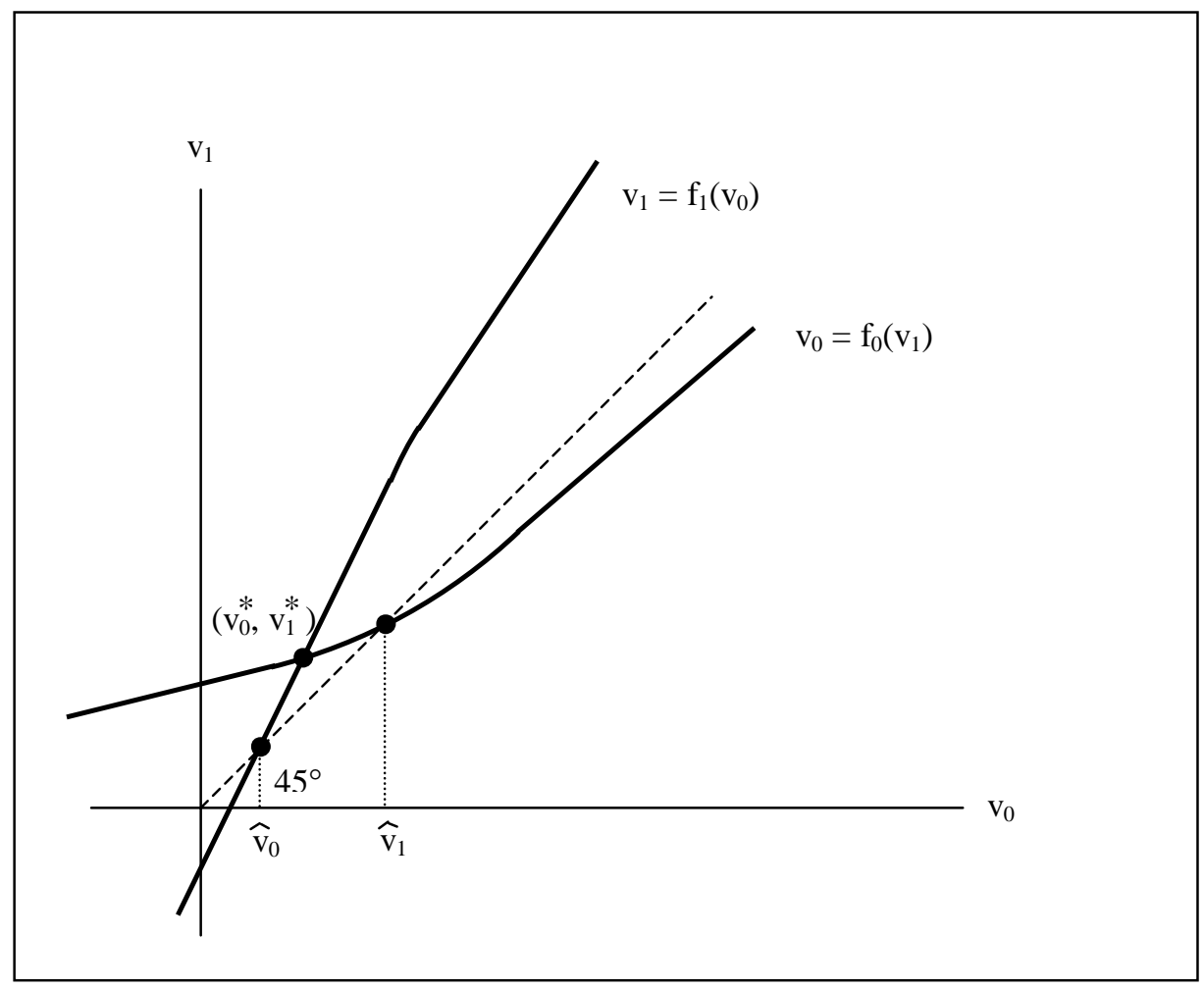

Figure A1: Uniqueness of Social Optimum

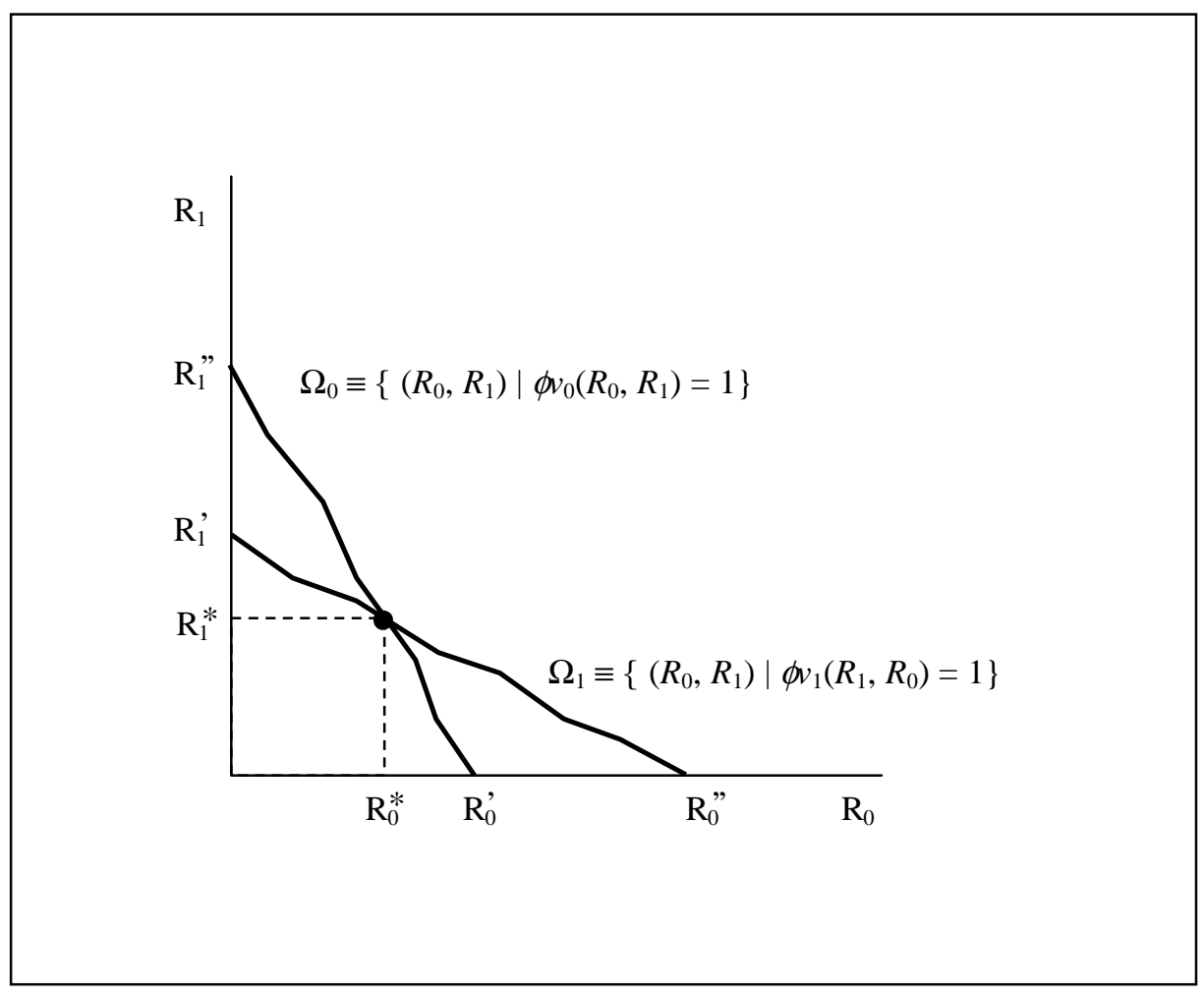

Figure A2: Uniqueness of Markov-Perfect Equilibrium 


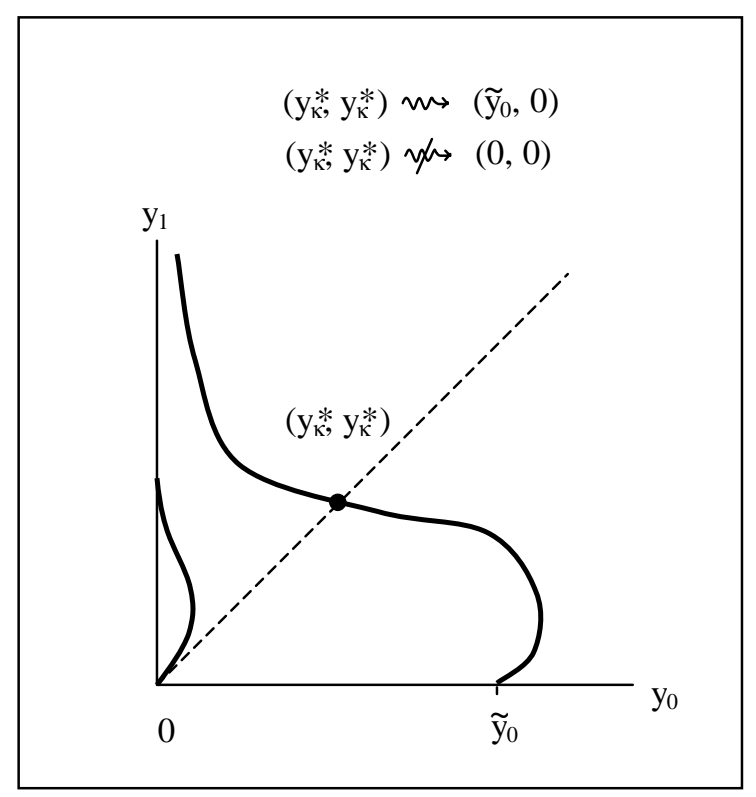

(A)

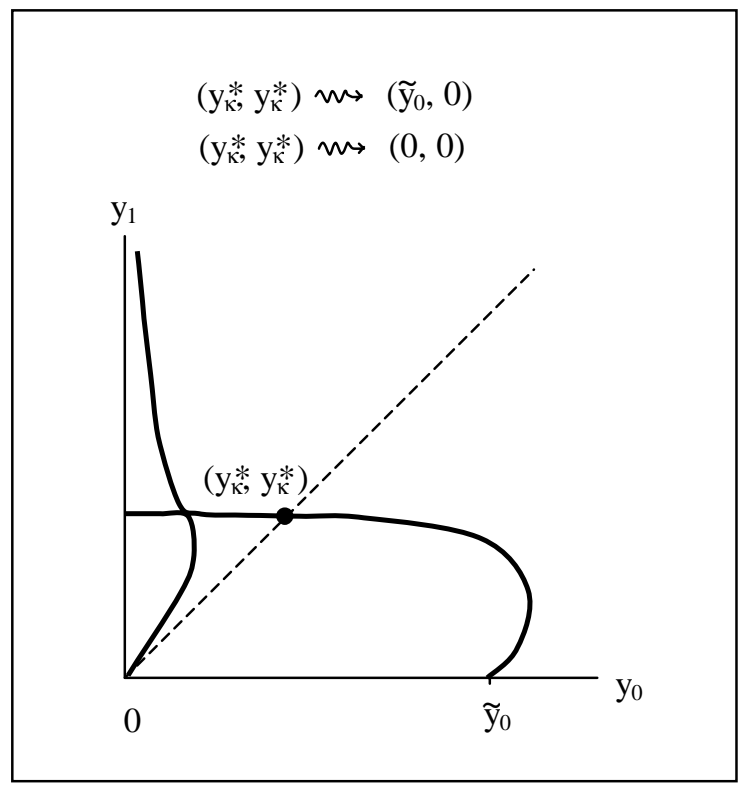

(B)

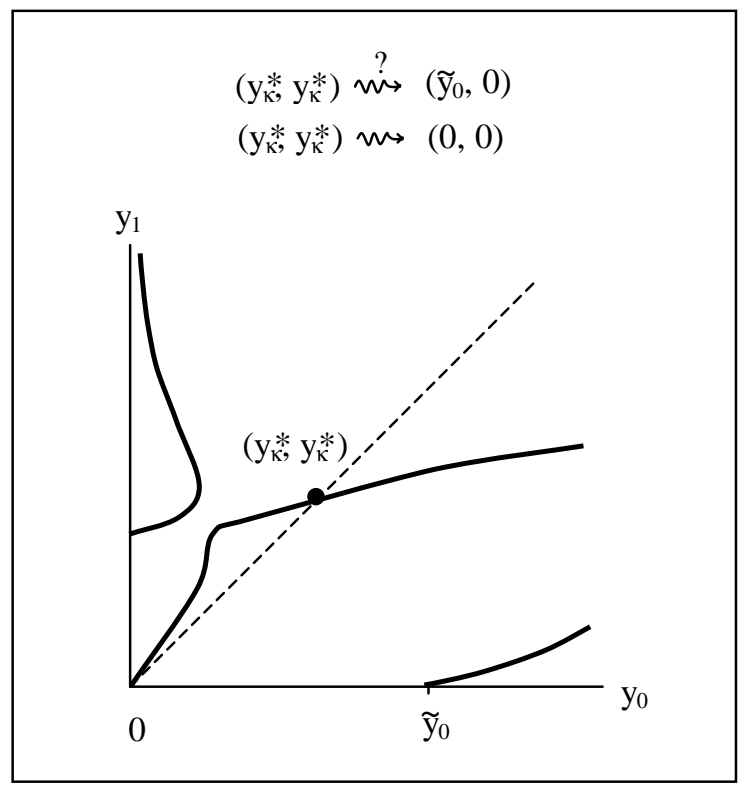

(C)

Figure A3: The Evolution of the set S in Proposition 4

Panel (A) corresponds to Case I in proof of Proposition 4 Panel (B) corresponds to Case II in proof of Proposition 4

Panel (C) corresponds to Case III in proof of Proposition 4 


\section{References}

[1] Aghion, Philippe and Peter Howitt, 1992. "A Model of Growth through Creative Destruction" Econometrica, 60(2), March, p323-51.

[2] Aghion, Philippe and Gilles Saint Paul, 1998. "Virtues of Bad Times: Interaction between Productivity Growth and Economic Fluctuations" Macroeconomic Dynamics, September, $2(3), \mathrm{p} 322-44$.

[3] Barlevy, Gadi, 2002. "The Sullying Effect of Recessions" Review of Economic Studies, 69 (1), January, p65-96.

[4] Barlevy, Gadi, 2004. "The Cost of Business Cycles under Endogenous Growth" American Economic Review, September, 93(4).

[5] Barlevy, Gadi and Dani Tsiddon, 2004. "Earnings Inequality and the Business Cycle" NBER Working Paper \#10469 and forthcoming, European Economic Review.

[6] Basu, Susanto, 1996. "Procyclical Productivity: Increasing Returns or Cyclical Utilization?" Quarterly Journal of Economics, 111(3), August, p719-51.

[7] Benhabib, Jess and Roger Farmer, 1994. "Indeterminacy and Increasing Returns" Journal of Economic Theory, 63(1), June, p19-41.

[8] Betts, Julian and Laurel McFarland, 1995. "Safe Port in a Storm: The Impact of Labor Market Conditions on Community College Enrollments" Journal of Human Resources, 30(4), p741-65.

[9] Burnside, Craig, Martin Eichenbaum, and Sergio Rebelo, 1993. "Labor Hoarding and the Business Cycle" Journal of Political Economy, 101(2), April, p245-73.

[10] Caballero, Ricardo and Mohamad Hammour, 1996. "On the Timing and Efficiency of Creative Destruction" Quarterly Journal of Economics, August, 111(3), p805-52.

[11] Caballero, Ricardo and Mohamad Hammour, 2004. "The Costs of Recessions Revisited: a Reverse-Liquidationist View" Review of Economic Studies.

[12] Canton, Eric and Harald Uhlig, 1999. "Growth and the Cycle: Creative Destruction versus Entrenchment" Journal of Economics, 69(3), p239-66.

[13] Comin, Diego and Mark Gertler, 2004. "Medium Term Business Cycles" Mimeo, New York University, July. 
[14] Cooper, Russell and John Haltiwanger, 1993. "The Aggregate Implications of Machine Replacement: Theory and Evidence" American Economic Review, June, 83(3), p181-186.

[15] Davis, Steven and John Haltiwanger, 1992. "Gross Job Creation, Gross Job Destruction, and Employment Reallocation" Quarterly Journal of Economics, August, 107(3), p819-63.

[16] Dellas, Harris and Plutarchos Sakellaris, 2003. "On the Cyclicality of Schooling: Theory and Evidence" Oxford Economic Papers, January, 55(1), p148-72.

[17] DeJong, David and Beth Ingram, 2001. "The Cyclical Behavior of Skill Acquisition" Review of Economic Dynamics, July, 4(3), p536-61.

[18] Fatas, Antonio, 2000. "Do Business Cycles Cast Long Shadows? Short-Run Persistence and Economic Growth" Journal of Economic Growth, 5(2), June, p147-62.

[19] Francois, Patrick and Huw Lloyd-Ellis, 2003. "Animal Spirits Through Creative Destruction" American Economic Review, June, 93(3), p530-50.

[20] Gomes, Joao, Jeremy Greenwood, and Sergio Rebelo, 2001. "Equilibrium Unemployment" Journal of Monetary Economics, 48(1), p109-52.

[21] Griliches, Zvi, 1984. "Comment on R\&D and Innovation: Some Empirical Findings" in RED, Patents, and Productivity, edited by Zvi Griliches, Chicago: University of Chicago Press, p148-149

[22] Griliches, Zvi, 1990. "Patent Statistics as Economic Indicators: a Survey" Journal of Economic Literature, December, 28(4), p1661-1707.

[23] Grossman, Gene and Elhanan Helpman, 1991. Innovation and Growth in the Global Economy. Cambridge, Mass: MIT Press.

[24] Hall, Robert 1991. "Labor Demand, Labor Supply, and Employment Volatility" NBER Macroeconomics Annual. Cambridge, Mass: MIT Press.

[25] Hall, Robert, 2000. "Reorganization" Carnegie Rochester Conference Series on Public Policy, 52(0), June, p1-22.

[26] Jones, Charles and John Williams, 2000. "Too Much of a Good Thing? The Economics of Investment in R\&D" Journal of Economic Growth, 5(1), March, p65-85.

[27] King, Ian and Arthur Sweetman, 2002. "Procyclical Skill Retooling and Equilibrium Search" Review of Economic Dynamics, 5(3), July, p704-17.

[28] Lucas, Robert, 1987. Models of Business Cycles. Oxford: Basil Blackwell. 
[29] Mansfield, Edwin, 1987. "Price Indexes for R and D Inputs, 1969-1983" Management Science, 33(1), January, p124-9.

[30] Mortensen, Dale and Chris Pissarides, 1994. "Job Creation and Job Destruction in the Theory of Unemployment" Review of Economic Studies, 61(3), July, p397-415.

[31] Mortensen, Dale, 2004. "Growth, Unemployment, and Labor Market Policy" Mimeo, Northwestern University.

[32] Ramey, Valerie, 1991. "Comment on Markups and the Business Cycle" NBER Macroeconomics Annual, vol 6, p134-9.

[33] Rivera-Batiz, Luis and Paul Romer, 1991. "Economic Integration and Endogenous Growth," Quarterly Journal of Economics, 106(2), May, p531-55.

[34] Rotemberg, Julio and Michael Woodford, 1999. "The Cyclical Behavior of Prices and Costs" in Handbook of Macroeconomics (1B), vol. 15, edited by John Taylor and Michael Woodford. Amsterdam: Elsevier Science, p1051-1135.

[35] Sepulveda, Facundo, 2002. "Training and Business Cycles" Mimeo, Michigan State University.

[36] Shleifer, Andrei, 1986. "Implementation Cycles" Journal of Political Economy, 94(6), December, p1163-90.

[37] Young, Alwyn, 1998. "Growth without Scale Effects" Journal of Political Economy, 106(1), February, p41-63. 